\title{
A Conceptual Design Approach of Coupled Shear Walls
}

\author{
Dipendu Bhunia, ${ }^{1}$ Vipul Prakash, ${ }^{2}$ and Ashok D. Pandey ${ }^{3}$ \\ ${ }^{1}$ Civil Engineering Group, BITS, Pilani 333031, India \\ ${ }^{2}$ Department of Civil Engineering, IIT Roorkee, Roorkee, India \\ ${ }^{3}$ Department of Earthquake Engineering, IIT Roorkee, Roorkee, India \\ Correspondence should be addressed to Vipul Prakash; vipulprakash@yahoo.com
}

Received 27 May 2013; Accepted 6 July 2013

Academic Editors: N. D. Lagaros and I. Smith

Copyright (C) 2013 Dipendu Bhunia et al. This is an open access article distributed under the Creative Commons Attribution License, which permits unrestricted use, distribution, and reproduction in any medium, provided the original work is properly cited.

Earthquake causes considerable damage to a large number of RCC high-rise buildings and tremendous loss of life. Therefore, designers and structural engineers should ensure to offer adequate earthquake resistant provisions with regard to planning, design, and detailing in high-rise buildings to withstand the effect of an earthquake and minimize disaster. As an earthquake resistant system, the use of coupled shear walls is one of the potential options in comparison with moment resistant frame (MRF) and shear wall frame combination systems in RCC high-rise buildings. Furthermore, it is reasonably well established that it is uneconomical to design a structure considering its linear behavior during earthquake. Hence, an alternative design philosophy needs to be evolved in the Indian context to consider the postyield behavior wherein the damage state is evaluated through deformation considerations. In the present context, therefore, performance-based seismic design (PBSD) has been considered to offer significantly improved solutions as compared to the conventional design based on linear response spectrum analysis.

\section{Introduction}

The growth of population density and shortage of land in urban areas are two major problems for all developing countries including India. In order to mitigate these two problems, the designers resort to high-rise buildings, which are rapidly increasing in number, with various architectural configurations and ingenious use of structural materials. However, earthquakes are the most critical loading condition for all land based structures located in the seismically active regions. The Indian subcontinent is divided into different seismic zones as indicated by IS 1893 (Part 1) [1], facilitating the designer to provide adequate protection against earthquake. A recent earthquake in India on January 26th, 2001 caused considerable damage to a large number of RCC high-rise buildings (number of storey varies from 4 to 15) and tremendous loss of life. The reasons were (a) most of the buildings had soft and weak ground storey that provided open space for parking, (b) poor quality of concrete in columns, and (c) poor detailing of the structural design (http://www.nicee.org/eqeiitk/uploads/EQR_Bhuj.pdf). Therefore, this particular incident has shown that designers and structural engineers should ensure to offer adequate earthquake resistant provisions with regard to planning, design, and detailing in highrise buildings to withstand the effect of an earthquake to minimize disaster.

As an earthquake resistant system, the use of coupled shear walls is one of the potential options in comparison with moment resistant frame (MRF) and shear wall frame combination systems in RCC high-rise buildings. MRF system and shear wall frame combination system are controlled by both shear behavior and flexural behavior; whereas, the behavior of coupled shear walls system is governed by flexural behavior. However, the behavior of the conventional beam both in MRF and shear wall frame combination systems is governed by flexural capacity, and the behavior of the coupling beam in coupled shear walls is governed by shear capacity. During earthquake, infilled brick masonry cracks in a brittle manner although earthquake energy dissipates through both inelastic yielding in beams and columns for MRF and shear wall frame combination systems; whereas, in coupled shear walls, earthquake energy dissipates through inelastic yielding in the coupling beams and at the base of the shear walls. Hence, amount of dissipation of earthquake 
energy and ductility obtained from both MRF and shear wall frame combination systems are less than those of coupled shear walls system in the high-rise buildings [211]. However, the Indian codes of practice governing the earthquake resistant design, such as IS 1893 (Part 1) [1] and IS 4326 [12], do not provide specific guidelines with regard to earthquake resistant design of coupled shear walls. On the other hand, IS 13920 [13] gives credence to the coupled shear walls as an earthquake resistant option but it has incorporated very limited design guidelines of coupling beams that are inadequate for practical applications. It requires further investigations and elaborations before practical use.

Further, it is reasonably well established that it is uneconomical to design a structure considering its linear behavior during earthquake as is recognized by the Bureau of Indian Standards $[1,12,13]$ currently in use. Hence, an alternative design philosophy needs to be evolved in the Indian context to consider the postyield behavior, wherein the damage state is evaluated through deformation considerations.

In the present context, therefore, performance-based seismic design (PBSD) can be considered to offer significantly improved solutions as compared to the conventional design based on linear response spectrum analysis. Performancebased seismic design (PBSD) implies design, evaluation, and construction of engineered facilities whose performance under common and extreme loads responds to the diverse needs and objectives of owners, tenants, and societies at large. The objective of PBSD is to produce structures with predictable seismic performance. In PBSD, multiple levels of earthquake and corresponding expected performance criteria are specified [16]. This aspect emphasizes nonlinear analyses for seismic design verification of any structure. This procedure gives some guidelines for estimating the possible local and global damages of structures. A retrofitted structure can be evaluated with the help of PBSD. Similarly, economics in the form of life-cycle cost along with construction cost of the structure is inherently included in PBSD [21].

On the basis of the aforesaid discussion, an effort has been made in this paper to develop a comprehensive procedure for the design of coupled shear walls.

\section{Investigation of Coupling Beam}

Coupled shear walls consist of two shear walls connected intermittently by beams along the height. The behavior of coupled shear walls is mainly governed by the coupling beams. The coupling beams are designed for ductile inelastic behavior in order to dissipate energy. The base of the shear walls may be designed for elastic or ductile inelastic behaviors. The amount of energy dissipation depends on the yield moment capacity and plastic rotation capacity of the coupling beams. If the yield moment capacity is too high, then the coupling beams will undergo only limited rotations and dissipate little energy. On the other hand, if the yield moment capacity is too low, then the coupling beams may undergo rotations much larger than their plastic rotation capacities. Therefore, the coupling beams should be provided with an optimum level of yield moment capacities. These moment capacities depend on the plastic rotation capacity available in beams. The geometry, rotations, and moment capacities of coupling beams have been reviewed based on previous experimental and analytical studies in this paper. An analytical model of coupling beam has also been developed to calculate the rotations of coupling beam with diagonal reinforcement and truss reinforcement.

2.1. Geometry of Coupling Beam. The behavior of the reinforced concrete coupling beam may be dominated by (1) shear or by (2) flexure as per ATC 40 [16], FEMA 273 [14], and FEMA 356 [15]. Shear is dominant in coupling beams when $\phi \leq 2[5]$ or $L_{b} / d_{b} \leq 4$.

There are various types of reinforcements in RCC coupling beams described as follows.

2.1.1. Conventional Reinforcement. Conventional reinforcement consists of longitudinal flexural reinforcement and transverse reinforcement for shear. Longitudinal reinforcement consists of top and bottom steel parallel to the longitudinal axis of the beam. Transverse reinforcement consists of closed stirrups or ties. If the strength of these ties $V_{s 1} \geq 3 / 4$ required shear strength of the beam and the spacing these ties $\leq d / 3$ over the entire length of the beam, then stable hysteresis occurs, and such transverse reinforcement is said to be conforming to the type now mandatory for new construction. If the transverse reinforcement is deficient either in strength or spacing then it leads to pinched hysteresis, and such reinforcement is said to be nonconforming [14-16].

According to IS 13920 [13], the spacing of transverse reinforcement over a length of $2 d$ at either end of a beam shall not exceed (a) $d / 4$ and (b) 8 times the diameter of the smallest longitudinal bar; however, it need not be less than $100 \mathrm{~mm}$. Elsewhere, the beam shall have transverse reinforcement at a spacing not exceeding $d / 2$. Whereas, the shear force to be resisted by the transverse reinforcement shall be the maximum of (1) calculated factored shear force as per analysis and (2) shear force due to formation of plastic hinges at both ends of the beam plus the factored gravity load on the span.

2.1.2. Diagonal Reinforcement. Diagonal reinforcement consists of minimum four bars per diagonal. It gives a better plastic rotation capacity compared to conventional coupling beam during an earthquake when $L_{b} / d_{b}<1.5$ as per Penelis and Kappos [5]. The provisions for diagonal reinforcement according to different codes have already been shown in Table 1. If the diagonal reinforcement is subjected to compressive loading it may buckle, in which case it cannot be relied on to continue resisting compressive loading. Under the action of reversing loads, reinforcement that buckles in compression with loading in one direction may be stressed in tension with loading in the opposite direction. This action may lead to low-cycle fatigue failure, so that the reinforcement cannot continue to resist tensile forces. For this reason, it is necessary to ensure that this reinforcement does not buckle. To prevent buckling due to compressive loading, the spacing between two adjacent diagonal bars should be greater than $\left(L_{d} / 12\right)$ [based on buckling condition of a column]. It has also been noticed from Englekirk [3] that diagonal 
TABLE 1: Rotation capacities for coupling beams controlled by flexure as per FEMA 273 [14] and FEMA 356 [15].

\begin{tabular}{|c|c|c|c|c|}
\hline \multirow{2}{*}{ Type of coupling beam } & \multirow{2}{*}{$\begin{array}{l}\text { Conditions } \\
\text { hear } / t_{w} L_{w} \sqrt{f_{c}^{\prime}}\end{array}$} & \multicolumn{3}{|c|}{ Plastic Rotation Capacity (Radians) } \\
\hline & & $\mathrm{IO}$ & LS & $\mathrm{CP}$ \\
\hline \multirow{2}{*}{$\begin{array}{l}\text { Conventional longitudinal reinforcement with } \\
\text { conforming transverse reinforcement }\end{array}$} & $\leq 3$ & 0.006 & 0.015 & 0.025 \\
\hline & $\geq 6$ & 0.005 & 0.010 & 0.015 \\
\hline \multirow{2}{*}{$\begin{array}{l}\text { Conventional longitudinal reinforcement with } \\
\text { non-conforming transverse reinforcement }\end{array}$} & $\leq 3$ & 0.006 & 0.012 & 0.020 \\
\hline & $\geq 6$ & 0.005 & 0.008 & 0.010 \\
\hline Diagonal Reinforcement & NA & 0.006 & 0.018 & 0.030 \\
\hline \multirow{2}{*}{ Flexure dominant steel coupling beam } & $b_{f} / 2 t_{f} \leq 52 / \sqrt{F_{y}}$ and $h / t_{w^{\prime}} \leq 418 / \sqrt{F_{y}}$ & $1 \theta_{y}$ & $6 \theta_{y}$ & $8 \theta_{y}$ \\
\hline & $b_{f} / 2 t_{f} \geq 65 / \sqrt{F_{y}}$ and $h / t_{w^{\prime}} \geq 640 / \sqrt{F_{y}}$ & $0.25 \theta_{y}$ & $2 \theta_{y}$ & $3 \theta_{y}$ \\
\hline
\end{tabular}

reinforcement should not be attempted in walls that are less than 16 in. (406.4 mm) thick. Unless strength is an overriding consideration, diagonally reinforced coupling beams should not be used.

2.1.3. Truss Reinforcement. Truss reinforcement represents a significant and promising departure from traditional coupling beam reinforcements. The primary load transfer mechanism of the system is represented by the truss taken to its yield capacity. A secondary load path is created by the global strut and tie. The load transfer limit state will coincide with the yielding of all of the tension diagonals, provided the soproduced compression loads do not exceed the capacity of the concrete compression strut. The yield strength of the primary truss is governed by the tensile strength of its diagonal; whereas, the primary truss transfer mechanism must include the shear travelling along the compression diagonal. According to Penelis and Kappos [5] and Galano and Vignoli [17], when $1.5 \leq L_{b} / d_{b} \leq 4$, truss reinforcement offers best seismic performance in comparison with conventional and diagonal reinforcements. This type of reinforcement has not been used till now. Detailing and placement problems must be carefully studied if their use is contemplated. Clearly, additional experimentation is required because the system appears to have merit, especially in thin walls [3].

When the postyield rotational level is much higher compared to rotational level for truss reinforcement, then steel beam can be provided as a coupling beam. There are two types of steel beams which are provided as coupling beams based on the following factors as per Englekirk [3], AISC [26], AISC [27], and AISC [28].

(a) Shear Dominant. In this beam, the shear capacity $V_{s p}$ is attained, and the corresponding bending moment is equal to $V_{s p} \times e / 2$ which must be less than $0.8 M_{p}$. The postyield deformation is accommodated by shear and it is presumed $e \leq 1.6 M_{p} / V_{s p}$; where $e=$ clear span of the coupling beam + $2 \times$ concrete cover of shear wall, $M_{p}=$ moment capacity of coupling beam, and $V_{s p}=$ shear capacity of coupling beam.

(b) Flexure Dominant. In this beam, the bending moment capacity $M_{p}$ is attained, and the corresponding shear force is equal to $2 M_{p} / e$ which must be less than $0.8 V_{s p}$. The postyield deformation is accommodated by flexure and it is presumed $e \geq 2.6 M_{p} / V_{s p}$.
2.2. Moment Capacity of Coupling Beam. The bending moment capacity of coupling beam depends on the geometry and material property of coupling beam. Bending moment capacity and shear force capacity of the coupling beam are related with each other. Englekirk [3], Park, and Paulay [4], Paulay [29], Harries et al. [30], AISC [26], AISC [27] and AISC [28] describe these capacities as follows.

2.2.1. Reinforced Concrete Coupling Beam. Shear capacity of coupling beam with conventional reinforcement can be calculated as

$$
\begin{aligned}
V_{s p} & =\frac{2 M_{p}}{L_{b}} \\
& =\frac{2 A_{s} f_{y}\left(d-d^{\prime}\right)}{L_{b}} .
\end{aligned}
$$

Whereas, shear capacity of coupling beam with diagonal reinforcement can be calculated as

$$
\begin{aligned}
V_{s p} & =V_{f}+V_{d 1} \\
& =\frac{2 M_{p}}{L_{b}}+2 T_{1} \sin \theta \\
& =\frac{2 A_{s} f_{y}\left(d-d^{\prime}\right)}{L_{b}}+\frac{4 A_{s}^{\prime \prime} f_{y}\left(\left(d_{b} / 2\right)-d^{\prime}\right)}{L_{d}},
\end{aligned}
$$

and shear capacity of coupling beam with truss reinforcement is as

$$
\begin{aligned}
V_{s p} & =2 V_{1}+V_{2} \\
& =2 T_{d}\left(\frac{d-d^{\prime}}{L_{d 1}}\right)+2 T^{\prime}\left(\frac{d-d^{\prime}}{L_{d 2}}\right) \\
& =\frac{2 A_{s}^{\prime \prime} f_{y}\left(d-d^{\prime}\right)}{L_{d 1}}+\frac{2\left(A_{s}-A_{s}^{\prime \prime}\right) f_{y}\left(d-d^{\prime}\right)}{L_{d 2}},
\end{aligned}
$$

where, $L_{d 1}=\sqrt{\left(L_{b} / 2\right)^{2}+\left(d-d^{\prime}\right)^{2}}$ and $L_{d 2}=$ $\sqrt{\left(L_{b}\right)^{2}+\left(d-d^{\prime}\right)^{2}}$. All three shear capacities must be less than equal to $\left[\left(0.35 f_{c}^{\prime} b_{b} w\left(d-d^{\prime}\right) / L_{d} \lambda_{0}\right]\right.$ or $\left[\left(0.35 f_{c}^{\prime} b_{b}\left(0.25 L_{d}\right)\left(d-d^{\prime}\right) / L_{d} \lambda_{0}\right]\right.$ or $\left[\left(0.08 f_{c}^{\prime} b_{b}\left(d-d^{\prime}\right) / \lambda_{0}\right]\right.$ 
TABLE 2: Rotation capacities for coupling beams controlled by shear as per FEMA 273 [14] and FEMA 356 [15].

\begin{tabular}{|c|c|c|c|c|}
\hline \multirow{2}{*}{ Type of coupling beam } & Conditions & \multicolumn{3}{|c|}{ Plastic Rotation Capacity (Radians) } \\
\hline & Shear $/ t_{w} L_{w} \sqrt{f_{c}^{\prime}}$ & $\mathrm{IO}$ & LS & $\mathrm{CP}$ \\
\hline \multirow{2}{*}{$\begin{array}{l}\text { Conventional longitudinal reinforcement with } \\
\text { conforming transverse reinforcement }\end{array}$} & $\leq 3$ & 0.006 & 0.012 & 0.015 \\
\hline & $\geq 6$ & 0.004 & 0.008 & 0.010 \\
\hline \multirow{2}{*}{$\begin{array}{l}\text { Conventional longitudinal reinforcement with } \\
\text { non-conforming transverse reinforcement }\end{array}$} & $\leq 3$ & 0.006 & 0.008 & 0.010 \\
\hline & $\geq 6$ & 0.004 & 0.006 & 0.007 \\
\hline Shear dominant steel coupling beam & & 0.005 & 0.11 & 0.14 \\
\hline
\end{tabular}

TABLE 3: Rotation capacities for coupling beams controlled by flexure as per ATC 40 [16].

\begin{tabular}{lccc}
\hline Type of coupling beam & \multicolumn{2}{c}{ Conditions } & \multicolumn{2}{c}{ Plastic Rotation Capacity (Radians) } \\
& Shear $/ b_{w} d \sqrt{f_{c}^{\prime}}$ & IO & LS \\
\hline Conventional longitudinal reinforcement with & $\leq 3$ & 0.006 & 0.015 \\
conforming transverse reinforcement & $\geq 6$ & 0.025 \\
Conventional longitudinal reinforcement with & $\leq 3$ & 0.05 & 0.010 \\
non-conforming transverse reinforcement & $\geq 6$ & 0.006 & 0.012 \\
Diagonal reinforcement & $\mathrm{NA}$ & 0.005 & 0.008 \\
\hline
\end{tabular}

which is based on the statement, that is, capacity of a concrete strut in cylindrical elements will diminish to a level of 30 to $35 \%$ of $f_{c}^{\prime}$ as cracking increases, where, $\lambda_{0}$ is member over strength factor of 1.25 .

2.2.2. Shear Dominant Steel Coupling Beam. For I-section type of steel coupling beam, shear capacity (permissible shear resisted by web only) for shear dominant steel coupling beam is denoted as $V_{s p}=0.6 F_{y} t_{w^{\prime}}\left(D-2 t_{f}\right)$ and moment capacity is $M_{p}=Z_{p} F_{y}$; where, $F_{y}$ is yield stress of structural steel, $t_{w^{\prime}}$ is web thickness, $D$ is the overall depth of the section, $t_{f}$ is flange thickness, and $Z_{p}$ is plastic section modulus.

2.2.3. Flexure Dominant Steel Coupling Beam. The transferable shear force $\left(V_{n f}\right)$ for flexure dominant steel coupling beam is the lesser of $2 M_{p} / e$ and $V_{s p}$; where, $M_{p}$ is the moment capacity which is $Z_{p} F_{y}$.

2.3. Rotational Capacity of Coupling Beam. The rotation capacity in coupling beams depends upon the type of coupling beam. When the rotational demand is greater than rotational capacity of RCC coupling beam with conventional flexural and shear reinforcement then diagonal or truss reinforcement type of coupling beam could be provided depending on the $L_{b} / d_{b}$ ratio. The steel coupling beam could be used when the rotational limit due to lateral loading exceeds the rotation capacity of RCC coupling beam with truss reinforcement. Various research works conducted by Paulay [31, 32], Hindi, and Sexsmith [33], FEMA356 [15], Xuan et al. [34] describe these capacities. ATC 40 [16], FEMA 273 [14], FEMA 356 [15], Galano and Vignoli [17], Chao et al. [35] and Englekirk [3] describe the following rotational capacities for various types of coupling beams considering the behavior controlled by flexure and shear during earthquake.
Tables 1, 2, 3, 4, 5, and 6 show these different rotational capacities for various coupling beams.

Shear $/ t_{w} L_{w} \sqrt{f_{c}^{\prime}}$ or Shear $/ b_{w} d \sqrt{f_{c}^{\prime}} \leq 3$ or $\geq 6$ is based on the aspect ratio $\left(L_{b} / d_{b}\right)$ of coupling beam and $b_{f} / 2 t_{f} \leq$ $52 / \sqrt{F_{y}}$ and $h / t_{w^{\prime}} \leq 418 / \sqrt{F_{y}}$ or $b_{f} / 2 t_{f} \geq 65 / \sqrt{F_{y}}$ and $h / t_{w}^{\prime} \geq 640 / \sqrt{F_{y}}$ are the conditions of the flexure dominant steel coupling beam to prevent local buckling.

Specifications in Tables 1, 2, 3, and 4 can be questioned on the basis of the following observations:

(1) As per Tables 1 and 2, the rotational capacities of beam depends on size of wall $\left(t_{w}, L_{w}\right)$ which is illogical.

(2) When shear span to depth ratio $\phi \leq 2$ or aspect ratio $L_{b} / d_{b} \leq 4$, the behavior of RCC coupling beams is controlled by shear. For this reason, as aspect ratio $\left(L_{b} / d_{b}\right)$ of diagonally reinforced beam is less than 1.5 , it means that the behavior of diagonally reinforced beam is controlled by shear. Whereas, Tables 1 and 3 show that diagonally reinforced coupling beam behavior is controlled by flexure which is not acceptable.

(3) Conventional longitudinal reinforcement with nonconforming transverse reinforcement is not accepted for new construction.

(4) If the behavior of coupling beam is controlled by flexure [aspect ratio $\left(L_{b} / d_{b}\right)$ is greater than 4 ], the length of the coupling beam is quite larger. According to Munshi and Ghosh [36], weakly coupled shear walls can be obtained for larger span of the coupling beam and the design results of this type of coupled shear walls are inconsistent with regard to the ductility and energy dissipation during earthquake motion. Hence, it can be said that rotational capacity 
TABLE 4: Rotation capacities for coupling beams controlled by shear as per ATC 40 [16].

\begin{tabular}{lccc}
\hline Type of coupling beam & \multicolumn{2}{c}{ Conditions } & \multicolumn{2}{c}{ Plastic Rotation Capacity (Radians) } \\
& Shear $/ b_{w} d \sqrt{f_{c}^{\prime}}$ & IO & LS \\
\hline Conventional longitudinal reinforcement with & $\leq 3$ & 0.006 & 0.012 \\
conforming transverse reinforcement & $\geq 6$ & 0.015 \\
Conventional longitudinal reinforcement with & $\leq 3$ & 0.004 & 0.008 \\
non-conforming transverse reinforcement & $\geq 6$ & 0.006 & 0.008 \\
\hline
\end{tabular}

TABLE 5: Rotation capacities for coupling beams as per Galano and Vignoli [17].

\begin{tabular}{lcc}
\hline Type of coupling beam & Aspect ratio & \multicolumn{2}{c}{ Rotation Capacity (Radians) } \\
& $L_{b} / d_{b}$ & $\theta_{\mathrm{Lu}}$ \\
\hline Conventional reinforcement & 1.5 & 0.051 \\
Diagonal reinforcement & 1.5 & 0.062 \\
Truss reinforcement & 1.5 & 0.084 \\
\hline
\end{tabular}

of coupling beams controlled by flexure as per ATC 40 [16], FEMA 273 [14], and FEMA 356 [15] cannot be accepted.

Similarly, specifications in Tables 5 and 6 can also be questioned on the basis of following observation.

For aspect ratio $L_{b} / d_{b}=1.5$, Galano and Vignoli [17] show different results regarding the ultimate rotation of various RCC coupling beams in comparison with the results made by Englekirk [3].

2.4. Analytical Program. The above study shows the inconsistent modeling parameters and inconsistent evaluative parameters. However, the behavior of coupled shear walls is controlled by the characteristics of various coupling beams. These characteristics depend on the following parameters:

(1) Beam span to depth ratio.

(2) Reinforcement details.

For this reason, more study is required to investigate into the limitations on behavior of coupling beams. Since computer programme ATENA2D [18] has some advantages in comparison with other software packages like SAP V 10.0.5 [23], ATENA2D [18] was considered to carry out this study. The advantages as well as disadvantage of ATENA2D [18] are as follows.

\subsection{Advantages of ATENA2D Are}

(i) Material, element, and reinforcement can be modeled individually, and

(ii) Geometric and material nonlinearity can be provided.

\subsection{Disadvantage of ATENA2D Is}

(i) Only static loading in one direction can be applied.

2.7. Reinforcement Layouts. There were eighteen RCC coupling beams and three different reinforcement layouts considered in the analytical program using ATENA2D [18]: (a) longitudinal with conforming transverse ties, (b) diagonal with conforming transverse ties around the main bars, and (c) truss with conforming transverse ties around the main bars. For each layout, the cross section of the coupling beam was considered as $600 \mathrm{~mm}$ (depth, $\left.d_{b}\right) \times 300 \mathrm{~mm}$ (width, $b_{b}$ ) and the beam span-depth ratio $\left(L_{b} / d_{b}\right)$ was considered as $1,1.5$, and 2.

2.8. Materials. The concrete (M20 grade) and steel (Fe 415 grade) were considered as two materials to model the coupled shear walls. The Poisson's ratio was considered as 0.2 . The unit-weight of concrete was considered as $23 \mathrm{kN} / \mathrm{m}^{3}$ and the unit-weight of steel was considered as $78.5 \mathrm{kN} / \mathrm{m}^{3}$. Both coupling beam and shear wall elements were assigned as 4noded quadrilateral elements; material in coupling beam was assigned as SBeta (inelastic), whereas, material in shear wall was assigned as plane stress elastic isotropic.

2.9. Investigative Model. Figure 1 and Table 7 describe the investigative models considered for ATENA2D [18] analysis. The behaviors of all eighteen coupling beams were governed by shear. The load (F) was calculated based on the shear force in beam and other parameters according to the provisions of FEMA 273 [14] and FEMA 356 [15].

The depth of the wall is considered as $L_{w}=4 \mathrm{~m}$, thickness of the wall is considered as $t_{w}=300 \mathrm{~mm}$, and minimum reinforcement in the shear wall is taken as $0.25 \%$ of its gross area@ $450 \mathrm{c} / \mathrm{c}$.

Here, Young's modulus for concrete in beam $=E_{c b}=$ $2.24 \times 10^{4} \mathrm{MPa}$, Young's modulus for steel in beam $=E_{s b}=$ $2.1 \times 10^{5} \mathrm{MPa}$, Young's modulus for concrete in wall $=E_{c w}=$ $2.24 \times 10^{4} \mathrm{MPa}$, and Young's modulus for steel in wall $=E_{s w}=$ $2.1 \times 10^{5} \mathrm{MPa}$.

2.10. Results and Discussions. The results using ATENA2D [18] have been tabulated in Table 8. It shows the comparison of rotational limit at CP level among FEMA 273 [14], FEMA 356 [15], and ATENA2D [18]. There are a lot of differences among the results of FEMA 273 [14], FEMA 356 [15], and ATENA2D [18]. The comparison has also been extended 
TABLE 6: Rotation capacities for coupling beams as per Englekirk [3].

\begin{tabular}{lcr}
\hline Type of coupling beam & Aspect ratio & Rotation Capacity (Radians) \\
& $L_{b} / d_{b}$ & $\theta_{u, \max }$ \\
\hline Conventional reinforcement & 1.5 & 0.02 \\
Diagonal reinforcement & 1.5 & 0.04 \\
Truss reinforcement & 1.5 & 0.06 \\
\hline
\end{tabular}

TABLE 7: (a) investigative model of coupling beam in ATENA2D [18] as per IS 13920 [13], IS 456 [19], SP-16 [20], FEMA 273 [14], and FEMA 356 [15]. (b) investigative model of coupling beam in ATENA2D [18] as per IS 13920 [13], IS 456 [19], SP-16 [20], FEMA 273 [14], and FEMA 356 [15]. (c) investigative model of coupling beam in ATENA2D [18] as per IS 13920 [13], IS 456 [19], SP-16 [20], FEMA 273 [14], and FEMA 356 [15].

(a)

\begin{tabular}{|c|c|c|c|c|c|}
\hline \multicolumn{6}{|c|}{ Coupling beam } \\
\hline \multirow{2}{*}{ Type } & \multirow{2}{*}{$L_{b}(\mathrm{~m})$} & \multirow{2}{*}{ Shear $/ t_{w} L_{w} \sqrt{f_{c}^{\prime}}$} & \multirow{2}{*}{$F(\mathrm{kN})$} & \multicolumn{2}{|c|}{ Reinforced steel } \\
\hline & & & & Longitudinal & Transverse \\
\hline \multirow{6}{*}{$\begin{array}{l}\text { Conventional beam with longitudinal and } \\
\text { transverse conforming reinforcement }\end{array}$} & \multirow{2}{*}{0.6} & $\leq 3$ & 585.4 & $8-10 \phi$ & 2-legged 16ф@200 c/c \\
\hline & & $\geq 6$ & 1171 & $8-20 \phi$ & 2-legged25ф@200 c/c \\
\hline & \multirow{2}{*}{0.9} & $\leq 3$ & 623.5 & $8-10 \phi$ & 2-legged 16ф@200 c/c \\
\hline & & $\geq 6$ & 1247 & $8-20 \phi$ & 2-legged 25ф@200 c/c \\
\hline & \multirow{2}{*}{1.2} & $\leq 3$ & 661.7 & $8-10 \phi$ & 2-legged 16ф@200 c/c \\
\hline & & $\geq 6$ & 1323 & $8-20 \phi$ & 2-legged25ф@200 c/c \\
\hline
\end{tabular}

(b)

\begin{tabular}{|c|c|c|c|c|c|}
\hline \multicolumn{6}{|c|}{ Coupling beam } \\
\hline \multirow{2}{*}{ Type } & \multirow{2}{*}{$L_{b}(\mathrm{~m})$} & \multirow{2}{*}{ Shear $/ t_{w} L_{w} \sqrt{f_{c}^{\prime}}$} & \multirow{2}{*}{$F(\mathrm{kN})$} & \multicolumn{2}{|c|}{ Reinforced steel } \\
\hline & & & & Longitudinal & Transverse \\
\hline \multirow{6}{*}{ Beam with diagonal reinforcement } & \multirow{2}{*}{0.6} & $\leq 3$ & 585.4 & $8-10 \phi+4-20 \phi$ as one diagonal & 2-legged16ф@200 c/c \\
\hline & & $\geq 6$ & 1171 & $8-20 \phi+4-30 \phi$ as one diagonal & 2-legged25ф@200 c/c \\
\hline & \multirow{2}{*}{0.9} & $\leq 3$ & 623.5 & $8-10 \phi+4-25 \phi$ as one diagonal & 2-legged16ф@200 c/c \\
\hline & & $\geq 6$ & 1247 & $8-20 \phi+4-30 \phi$ as one diagonal & 2-legged25 $@ @ 200$ c/c \\
\hline & \multirow{2}{*}{1.2} & $\leq 3$ & 661.7 & $8-10 \phi+4-25 \phi$ as one diagonal & 2-legged16ф@200 c/c \\
\hline & & $\geq 6$ & 1323 & $8-20 \phi+4-35 \phi$ as one diagonal & 2-legged25ф@200 c/c \\
\hline
\end{tabular}

(c)

\begin{tabular}{|c|c|c|c|c|c|}
\hline \multicolumn{6}{|c|}{ Beam } \\
\hline \multirow{2}{*}{ Type } & \multirow{2}{*}{$L_{b}(\mathrm{~m})$} & \multirow{2}{*}{ Shear $/ t_{w} L_{w} \sqrt{f_{c}^{\prime}}$} & \multirow{2}{*}{$F(\mathrm{kN})$} & \multicolumn{2}{|c|}{ Reinforced steel } \\
\hline & & & & Longitudinal & Transverse \\
\hline \multirow{6}{*}{ Beam with truss reinforcement } & \multirow{2}{*}{0.6} & $\leq 3$ & 585.4 & $8-10 \phi+4-30 \phi$ as one truss & 2-legged16ф@200 c/c \\
\hline & & $\geq 6$ & 1171 & $8-20 \phi+4-45 \phi$ as one truss & 2-legged25ф@200 c/c \\
\hline & \multirow{2}{*}{0.9} & $\leq 3$ & 623.5 & $8-10 \phi+4-30 \phi$ as one truss & 2-legged 16ф@200 c/c \\
\hline & & $\geq 6$ & 1247 & $8-20 \phi+4-40 \phi$ as one truss & 2-legged 25ф@@200 c/c \\
\hline & \multirow{2}{*}{1.2} & $\leq 3$ & 661.7 & $8-10 \phi+4-30 \phi$ as one truss & 2-legged 16ф@200 c/c \\
\hline & & $\geq 6$ & 1323 & $8-20 \phi+4-40 \phi$ as one truss & 2-legged 25 \\
\hline
\end{tabular}

for considering ATC 40's [16] provisions. There are also big differences between the results of ATC 40 [16] and ATENA2D [18] shown in Table 9. It may be because of the limitations of ATENA2D [18] software. However, it is unexpected in FEMA 273 [14], FEMA 356 [15], and ATC 40 [16] that the rotational limit is more or less same, whereas, the parameters considered for calculation of shear strength are different. Therefore, it can be said that the parameters given in FEMA 273 [14], FEMA 356 [15], and ATC 40 [16] are questionable which have already been discussed in this paper. It has also been observed from Tables 8 and 9 that crack width in beam is quite significant although the rotational values in ATENA2D [18] are unexpectedly varying with FEMA 273 [14], FEMA 356 [15], and ATC 40 [16].

Hence, the results obtained from the above study using ATENA2D [18] were found unsatisfactory. Therefore, a new model has been created with some assumptions in the manner shown in Figure 2 to carryout further study. 


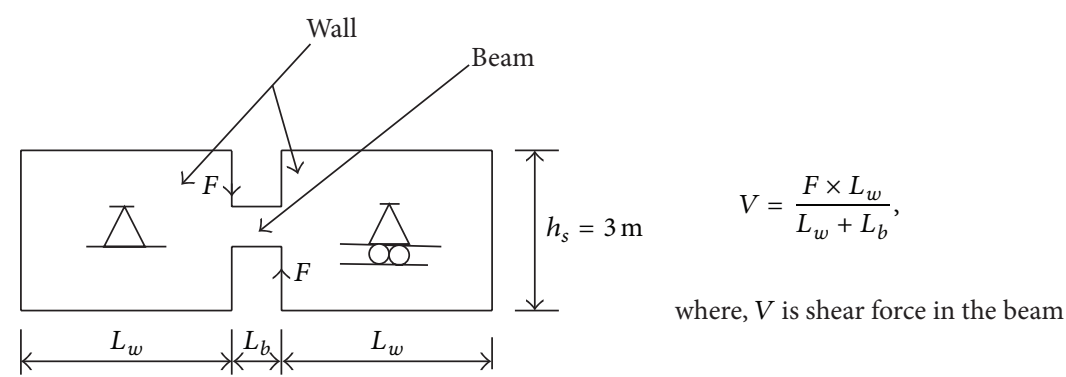

FIGURE 1: Initial sketch of the analytical model.

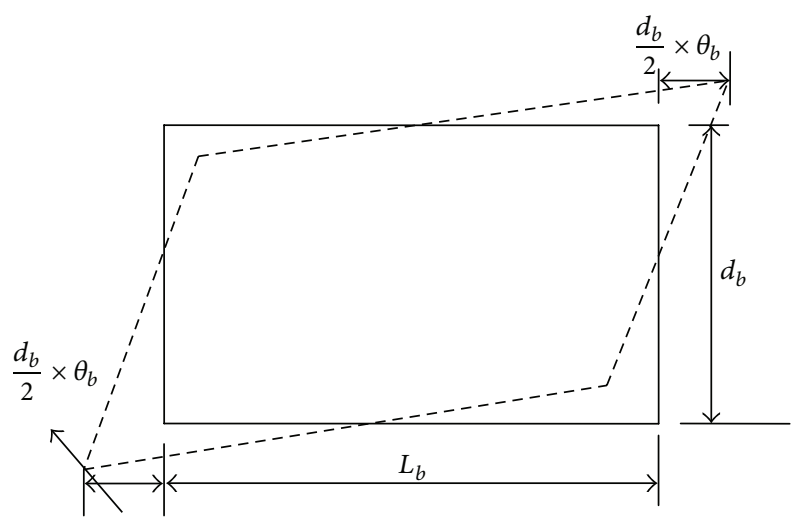

Figure 2: Schematic diagram of coupling beam.

\subsection{Assumptions}

(i) The effect of gravity loads on the coupling beams has been neglected.

(ii) Deflection of the coupling beam occurs due to lateral loading.

(iii) Contra flexure occurs at the mid-span of the coupling beam.

(iv) The confined concrete, due to the confining action is provided by closely spaced transverse reinforcement in concrete, is assumed to govern the strength.

Total elongation in the horizontal direction (Figure 2) due to lateral loading can be written as

$$
\Delta L_{b}=d_{b} \times \theta_{b}
$$

and strain in the concrete

$$
\varepsilon_{c}=\frac{\Delta L_{b}}{L_{b}}
$$

Hence, considering (4) and (5) the following equation can be written as

$$
\text { coupling beam rotation, } \theta_{b}=\frac{\varepsilon_{c} \times L_{b}}{d_{b}} \text {. }
$$

The results, considering (6) with maximum strain in confined concrete $\left(\varepsilon_{\mathrm{cu}}\right)$ of 0.02 (Confining action is provided by closely spaced transverse reinforcement in concrete as per ATC 40 [16]), have been tabulated in Table 10 .

It can be observed from Table 10 that the values obtained as per (6) have similar trend with the values specified by ATC 40 [16], FEMA 273 [14], FEMA 356 [15], Galano and Vignoli [17], and Englekirk [3].

Based on the above study, Table 11 has been prepared containing modified parameters governing the coupling beam characteristics, which are also considered for the developments of the design technique discussed below. As design technique is based on collapse prevention (CP) level of structure, plastic rotation capacity given in Table 11 is for CP level only.

\section{Proposed Design Technique}

In this paper an attempt has been made to develop a technique to design coupled shear walls considering its ideal seismic behavior (stable hysteresis with high earthquake energy dissipation). For preparing this design technique, symmetrical coupled shear walls have been considered. Design/capacity curve of coupled shear walls is obtained at the collapse mechanism of the structure based on this technique. This technique is applied to both fixed base and pinned base coupled shear walls. To start with, this technique is useful in selecting the preliminary dimensions of symmetrical coupled shear walls and subsequently arrives at a final design stage. Further, this technique is particularly useful for designer, consultant and practicing engineer who have no access to sophisticated software packages. A case study has been done implementing the technique with the help of Microsoft Excel Spreadsheet and the results have also been validated.

3.1. Proposed Formulation. In Figure 3, the coupled shear walls are subjected to a triangular variation of loading with amplitude $F_{1}$ at the roof level. The value of $F_{1}$ is obtained corresponding to the CP level of structure. Subsequently, the base shear and roof displacement can be determined. The procedure involving Figure 3, the assumptions, steps, and mathematical calculation with initial value of $F_{1}$ as unity have been illustrated as in Figure 3. 


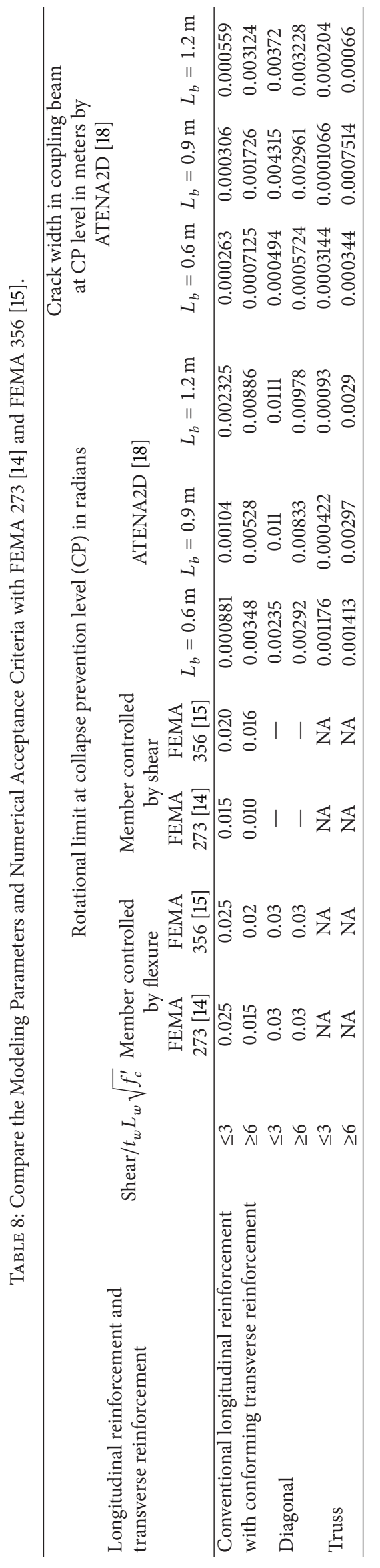




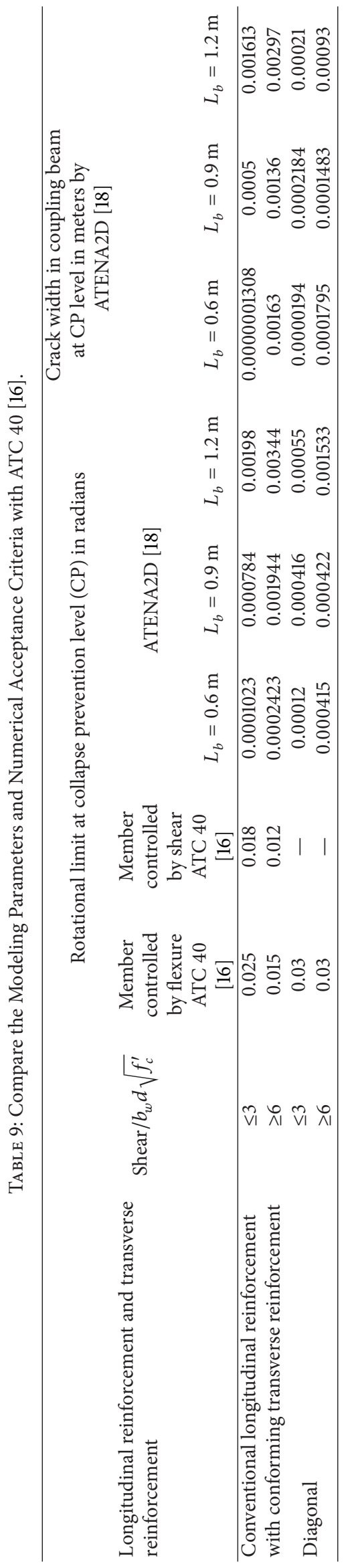




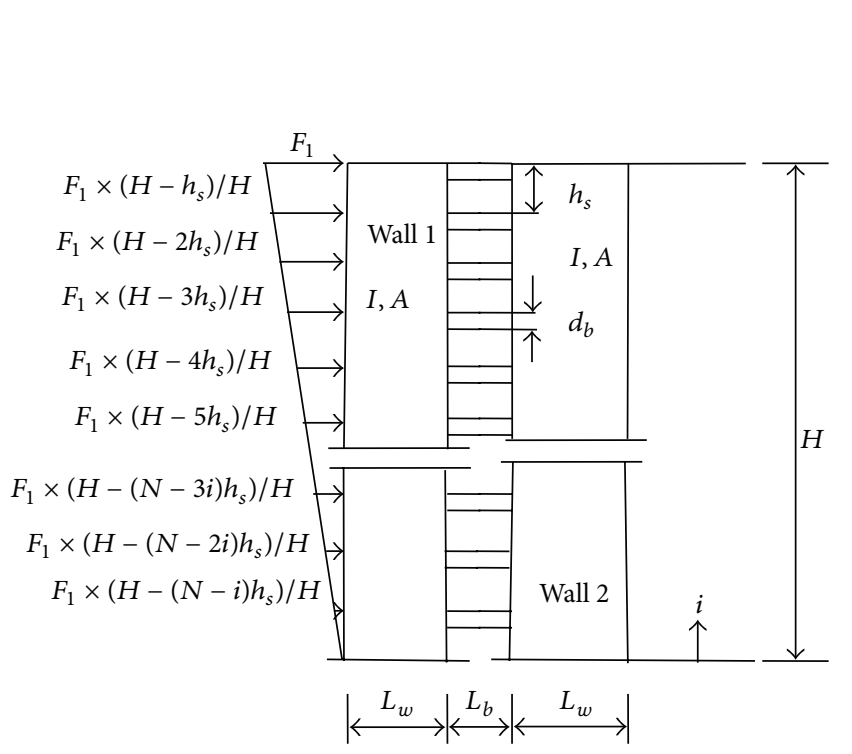

(a)

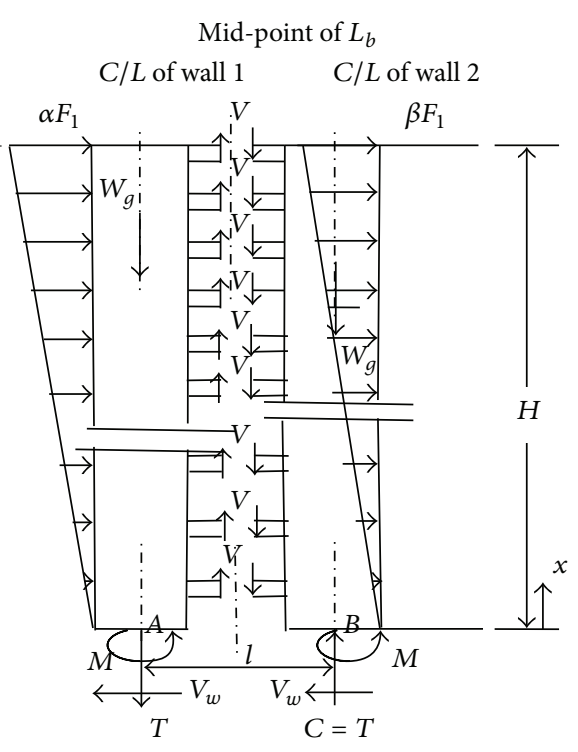

(b)

FIGURE 3: (a) Coupled shear walls. (b) Free body diagram of coupled shear walls.

TABLE 10: Maximum rotations in radians.

\begin{tabular}{|c|c|c|c|c|c|}
\hline $\begin{array}{l}\text { Type of } \\
\text { reinforcement }\end{array}$ & $L_{b} / d_{b}$ & Value as per (6) & $\begin{array}{l}\text { Galano and } \\
\text { Vignoli [17] }\end{array}$ & Englekirk [3] & $\begin{array}{c}\text { ATC40 [16], FEMA } \\
273[14] \text { and FEMA } \\
356[15]\end{array}$ \\
\hline Diagonal & $<1.5$ & $<0.03$ & 0.062 & 0.04 & 0.03 \\
\hline Truss & 1.5 to 4.0 & 0.03 to 0.08 & 0.084 & 0.06 & - \\
\hline
\end{tabular}

3.2. Assumptions. The following assumptions are adopted for the design technique to obtain the ideal seismic behavior of coupled shear walls.

(1) The analytical model of coupled shear walls is taken as two-dimensional entity.

(2) Coupled shear walls exhibit flexural behavior.

(3) Coupling beams carry axial forces, shear forces, and moments.

(4) The axial deformation of the coupling beam is neglected.

(5) The effect of gravity loads on the coupling beams is neglected.

(6) The horizontal displacement at each point of wall 1 is equal to the horizontal displacement at each corresponding point of wall 2 due to the presence of coupling beam.

(7) The curvatures of the two walls are same at any level.

(8) The point of contra flexure occurs at mid-point of clear span of the beam.

(9) The seismic design philosophy requires formation of plastic hinges at the ends of the coupling beams. All coupling beams are typically designed identically with identical plastic moment capacities. Being lightly loaded under gravity loads they will carry equal shear forces before a collapse mechanism is formed. All coupling beams are, therefore, assumed to carry equal shear forces.

(10) In the collapse mechanism for coupled shear walls, plastic hinges are assumed to form at the base of the wall and at the two ends of each coupling beam. In the wall the elastic displacements shall be small in comparison to the displacements due to rotation at the base of the wall. If the elastic displacements in the wall are considered negligible then a triangular displaced shape occurs. This is assumed to be the distribution displacement/velocity/acceleration along the height. The acceleration times the mass/weight at any floor level gives the lateral load. Hence, the distribution of the lateral loading is assumed as a triangular variation, which conforms to the first mode shape pattern.

3.3. Steps. The following iterative steps are developed in this thesis for the design of coupled shear walls.

(1) Selection of a particular type of coupling beam and determining its shear capacity.

(2) Determining the fractions of total lateral loading subjected on wall 1 and wall 2.

(3) Determining shear forces developed in coupling beams for different base conditions. 
TABLE 11: Modified parameters governing the coupling beam characteristics controlled by shear.

\begin{tabular}{|c|c|c|c|c|c|}
\hline \multirow{2}{*}{$\begin{array}{l}\text { Type of coupling } \\
\text { beam }\end{array}$} & \multirow{2}{*}{ Shear span to depth ratio } & \multirow{2}{*}{$L_{b} / d_{b}$} & \multirow{2}{*}{ Type of detailing } & \multicolumn{2}{|c|}{ Plastic Rotation Capacity (Radians) } \\
\hline & & & & Shear $/ b_{w} d \sqrt{f_{c}^{\prime}}$ & $\mathrm{CP}$ \\
\hline \multirow{4}{*}{$\begin{array}{l}\text { Reinforced concrete } \\
\text { coupling beam }\end{array}$} & \multirow{4}{*}{$\phi \leq 2$} & \multirow{2}{*}{ No limit } & \multirow{3}{*}{$\begin{array}{l}\text { Conventional longitudinal reinforcement } \\
\text { with conforming transverse reinforcement } \\
\text { Diagonal Reinforcement (strength is an } \\
\text { overriding consideration and thickness of } \\
\text { wall should be greater than } 406.4 \mathrm{~mm} \text { ) }\end{array}$} & $\leq 3$ & 0.015 \\
\hline & & & & $\geq 6$ & 0.010 \\
\hline & & $<1.5$ & & - & $<0.03$ \\
\hline & & 1.5 to 4.0 & $\begin{array}{l}\text { Truss Reinforcement (additional } \\
\text { experimentation is required) }\end{array}$ & - & $0.03-0.08$ \\
\hline Steel coupling beam & $e \leq 1.6 M_{p} / V_{s p}$ & & Shear dominant & - & $0.15 / L_{b}$ \\
\hline
\end{tabular}

(4) Determining wall rotations in each storey.

(5) Checking for occurrence of plastic hinges at the base of the walls when base is fixed. For walls pinned at the base this check is not required.

(6) Calculating coupling beam rotation in each storey.

(7) Checking whether coupling beam rotation lies at collapse prevention level.

(8) Calculating base shear and roof displacement.

(9) Modifying the value of $F_{1}$ for next iteration starting from Step (2) if Step (7) is not satisfied.

3.4. Mathematical Calculation. The steps which are described above have been illustrated in this section as follows.

Step 1. The type of coupling beam can be determined as per Table 11, and shear capacity can be calculated as per Section 2.2

Step 2. In Figure 3(b), free body diagram of coupled shear walls has been shown; $\alpha$ and $\beta$ are fractions of total lateral loading incident on wall 1 and wall 2 , respectively, such that,

$$
\alpha+\beta=1.0 \text {. }
$$

For symmetrical coupled shear walls, moments of inertias of two walls are equal for equal depths and thicknesses at any level. Further, curvatures of two walls are equal at any level. Hence based on the Assumption (7), equation (7) can be written as

$$
\alpha=\beta=0.5 \text {. }
$$

Step 3. In this step, it is explained how to calculate the shear force developed in the coupling beams for different types of boundary conditions. CSA [25] and Chaallal et al. [37] defined the degree of coupling which is written as

$$
\mathrm{DC}=\frac{T \times l}{M_{\mathrm{ot}}},
$$

where, $l=L_{w}+L_{b}$; $T$ is the axial force due to lateral loading and $M_{\mathrm{ot}}$ is total overturning moment at the base of the wall produced due to lateral loading. For fixed base condition DC varies from 0 to 1 and (9) can also be written as

$$
\mathrm{DC}=k^{\prime} \frac{\left(d_{b}\right)^{a}}{\left(L_{w}\right)^{b} \times\left(L_{b}\right)^{c}} .
$$

TABLE 12: Values of constant $k^{\prime}$ and exponents $a, b$ and $c$.

\begin{tabular}{lcccc}
\hline$N$ & $k^{\prime}$ & $a$ & $b$ & $c$ \\
\hline 6 & 2.976 & 0.706 & 0.615 & 0.698 \\
10 & 2.342 & 0.512 & 0.462 & 0.509 \\
15 & 1.697 & 0.352 & 0.345 & 0.279 \\
20 & 1.463 & 0.265 & 0.281 & 0.190 \\
30 & 1.293 & 0.193 & 0.223 & 0.106 \\
40 & 1.190 & 0.145 & 0.155 & 0.059 \\
\hline
\end{tabular}

The above equation (10) is proposed by Chaallal et al. [37]; $N$ is the total number of storeys, $k^{\prime}$ is constant, and $a, b$, and $c$ are exponents which are given in Table 12.

So based upon the above criteria and considering (9) and (10), shear force developed in the coupling beam could be determined as follows.

For fixed base condition following equation can be written as

$$
C=T=\sum_{i=1}^{N} V_{i}=\frac{M_{\mathrm{ot}}}{l} \times k^{\prime} \frac{\left(d_{b}\right)^{a}}{\left(L_{w}\right)^{b} \times\left(L_{b}\right)^{c}}
$$

where, $M_{\mathrm{ot}}$ is total overturning moment at the base due to the lateral loading.

Therefore, based on the Assumption (9) shear force in coupling beam at each storey is

$$
V=\frac{\sum_{i=1}^{N} V_{i}}{N}
$$

Pinned Base Condition. In this study, pinned base condition has been introduced as one of the possible boundary conditions for coupled shear walls. It can be constructed by designing the foundation for axial load and shear force without considering bending moment. It is expected that stable hysteresis with high earthquake energy dissipation can be obtained for considering this kind of base condition.

DC is 1 for pinned base condition from (9). Hence, the equation can be written as

$$
C=T=\sum_{i=1}^{N} V_{i}=\frac{M_{\mathrm{ot}}}{l}
$$


Therefore, based on the Assumption (9) shear force in coupling beam at each storey is

$$
V=\frac{\sum_{i=1}^{N} V_{i}}{N}
$$

Step 4. After obtaining $\alpha, \beta$, and $V$ at each storey for the particular value of $F_{1}$, bending moment values in each storey could be determined for each wall. Subsequently, curvature diagram for each wall is generated by using moment area method as adopted in the Microsoft excel spreadsheet; which is required to determine the wall rotation in each storey. The following equations are considered to calculate the wall rotation.

Overturning moment at a distance " $x$ " from base with respect to each wall can be written as

$$
M_{\mathrm{ot}}(x)=\sum_{j=0}^{N-i}\left\{0.5 \times \frac{F_{1}}{H}\left(H-j h_{s}\right)\left(H-x-j h_{s}\right)\right\},
$$

where, $i$ is storey number and it is considered from the base as $0,1,2,3, \ldots, N$.

Resisting moment in wall due to shear force in the coupling beam at a distance " $x$ " from base can be written as

$$
M_{\mathrm{wr}}(x)=\left(\frac{L_{w}}{2}+\frac{L_{b}}{2}\right) \sum_{j=i}^{N} V_{j},
$$

where, net moment in the wall at a distance " $x$ " from base, generated due to overturning moment and moment due to shear force in the coupling beam, can be written as

$$
M_{\text {net }}(x)=M_{\mathrm{ot}}(x)-M_{\mathrm{wr}}(x) .
$$

Wall rotation at $i$ th storey for fixed base can be written as

$$
\theta_{w i}=\frac{\int_{0}^{i h_{s}} M_{\text {net }}(x) d x}{E_{c} I}
$$

where,

$$
I=\frac{t_{w} \times L_{w}^{3}}{12}
$$

For plastic hinge rotation at the fixed base of wall or rotation at the pinned base of wall, (18) could be written as

$$
\theta_{w i}=\frac{\int_{0}^{i h_{s}} M_{\mathrm{net}}(x) d x}{E_{c} I}+\theta_{w 0},
$$

where, $\theta_{w 0}$ is the plastic hinge rotation at the fixed base of wall or rotation at the pinned base of wall.

Step 5. Consider (i) Tensile forces at the base of wall $1(T)$ as well as compressive forces at the base of wall $2(C)$ are calculated due to lateral loading.

(ii) Compressive loads at the bases of wall 1 and wall 2 are calculated due to gravity loading.

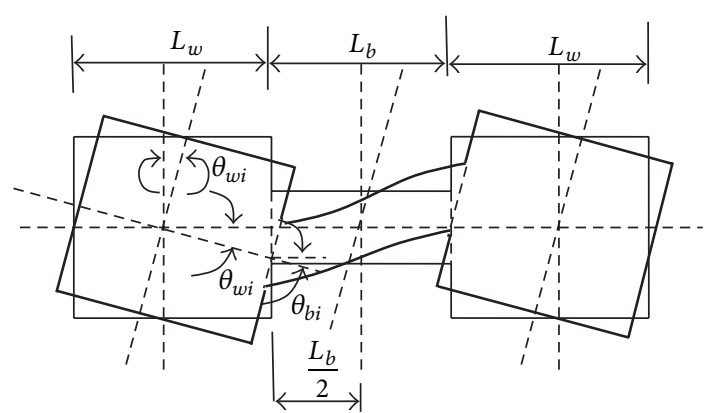

FIgURE 4: Deformed shape of a $i$ th storey symmetrical coupled shear walls.

(iii) Net axial forces at the bases of wall 1 and wall 2 are calculated, that is, Net axial force $=$ Tensile or Compressive force due to lateral loading ( $T$ or $C$ ) \pm Compressive load due to gravity loading.

(iv) Then, according to these net axial forces for the particular values of $f_{c k}, b_{b}, d$, and $p$, the yield moment values at the bases of wall 1 and wall 2 can be determined from $P-M$ interaction curve $[2,19]$. Where $f_{c k}, b_{b}, d$, and $p$ are yield strength of concrete, breadth of a section, depth of that section and percentage of minimum reinforcement in that particular section, respectively; and $P$ is the axial force and $M$ is the moment; here, net axial force is considered as $P$ in the $P-M$ interaction curve.

(v) Therefore, if calculated bending moment value at any base of the two walls is greater than yield moment value, plastic hinge at that base would be formed, otherwise no plastic hinge would be formed.

Step 6. The rotation of coupling beam in each storey is determined in Figure 4.

Rotation of coupling beam at $i$ th storey for symmetrical walls [3] as per Figure 4 is given by

$$
\theta_{b i}=\theta_{w i}\left(1+\frac{L_{w}}{L_{b}}\right)
$$

where, $\theta_{w i}$ is rotation of wall at $i$ th storey and can be calculated as per (18), $L_{w}=$ depth of wall, $L_{b}=$ length of coupling beam.

For plastic hinge rotation at the fixed base of wall or real hinge rotation at the pinned base of wall, (21) could be written as:

$$
\theta_{b i}=L_{w b}\left\{\theta_{w i}\right\},
$$

where, $\theta_{w i}$ can be calculated as per (20) for fixed base of wall or for pinned base of wall and

$$
L_{w b}=\left(1+\frac{L_{w}}{L_{b}}\right)
$$

Step 7. The rotational limit for collapse prevention level of different types of RCC coupling beams and steel beams are given in Table 11. The task was to check whether the rotations of beams attained their rotational limit of CP level at the collapse mechanism of the structure simultaneously. 


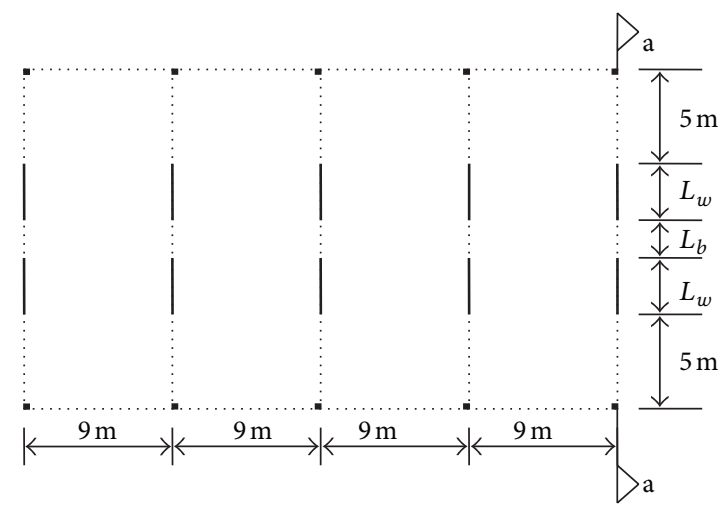

(a)

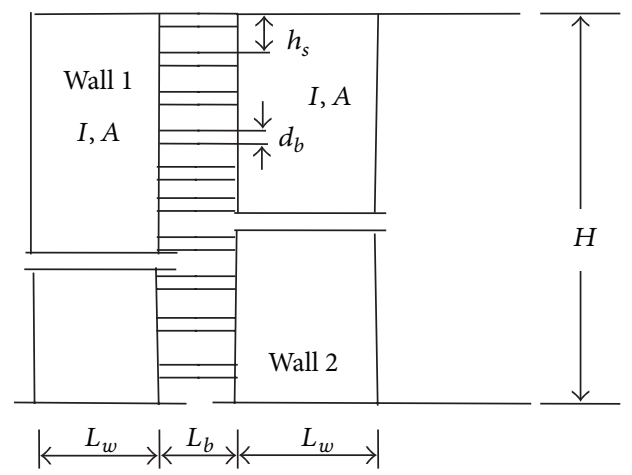

(b)

Figure 5: (a) Plan view of building. (b) Coupled shear walls at section "a-a".

Step 8. The roof displacement can be calculated as per the following equations

$$
\Delta_{\text {roof }}=h_{s} \times\left(\sum_{i=0}^{N} \theta_{w i}\right),
$$

where, displacement at $i$ th storey can be calculated as

$$
\Delta_{i}=h_{s} \times\left(\sum_{j=0}^{i} \theta_{w j}\right) .
$$

The base shear can be calculated as follows:

$$
V_{B}=\frac{F_{1} \times(N+1)}{2} \text {. }
$$

Step 9. The $F_{1}$ is modified as follows when the condition of Step 7 is not satisfied.

To obtain the collapse mechanism of the structure, it is required to increase $F_{1}$ with equal increment until all coupling beams attain their rotation limit of CP level simultaneously.

3.5. Validation of the Proposed Design Technique. The following numerical example has been considered to validate the propose design technique. In this study, plan and elevation with dimensions and material properties of the coupled shear walls have been adopted as given in Chaallal et al. [37].

3.6. Numerical Example. The coupled shear walls considered here are part of a 20-storey office building (Figure 5). It is subjected to triangular variation of lateral loading. The dimension and material properties are tabulated in Table 13. Dead loads and live loads are discussed in the following section. A comparison of the results regarding design/capacity curve (Figure 7) and ductility (27) obtained from the proposed design technique with the results obtained in SAP V 10.0.5 [23] and DRAIN-3DX [22] software packages may, thus, be required. For obtaining more perfection about the results, these two softwares have been considered in Table 13 simultaneously.

Figures 5(a) and 5(b) show the plan and sectional elevation of the coupled shear wall building, respectively.
TABLE 13: Dimensions and material properties of coupled shear walls for validation of proposed design technique.

\begin{tabular}{lc}
\hline Depth of the wall $\left(L_{w}\right)$ & $4 \mathrm{~m}$ \\
Length of coupling beam $\left(L_{b}\right)$ & $1.8 \mathrm{~m}$ \\
Depth of coupling beam $\left(d_{b}\right)$ & $600 \mathrm{~mm}$ \\
Number of storeys $(N)$ & 20 \\
Wall thickness $\left(t_{w}\right)$ & $300 \mathrm{~mm}$ \\
Width of coupling beam $\left(b_{b}\right)$ & $300 \mathrm{~mm}$ \\
Storey height $\left(h_{s}\right)$ & $3.0 \mathrm{~m}$ \\
Modulus of concrete $\left(E_{c}\right)$ & $27.0 \mathrm{GPa}$ \\
Modulus of steel $\left(E_{s}\right)$ & $200.0 \mathrm{GPa}$ \\
Steel yield strength $\left(f_{y}\right)$ & $415 \mathrm{Mpa}$ \\
\hline
\end{tabular}

3.6.1. Loading Consideration. Dead loads (DL) of $6.7 \mathrm{kN} / \mathrm{m}^{2}$ and live loads (LL) of $2.4 \mathrm{kN} / \mathrm{m}^{2}$ have been considered as suggested in Chaallal et al. [37]. Total gravity loading on coupled shear walls at section "a-a" has been calculated as the sum of dead load plus 25\% LL as per IS 1893 (part 1) [1] for floor; however, in case of roof only dead load is considered.

3.6.2. Modeling of Coupled Shear Walls in Proposed Design Technique. The modeling of coupled shear walls involving Figure 3, assumptions, and steps with mathematical calculation are already described in Section 3.1.

3.6.3. Modeling of Coupled Shear Walls in SAP and DRAIN3DX. Wide column frame analogy [38] has been considered for modeling of coupled shear walls in SAP V 10.0.5 [23] and DRAIN-3DX [22] as given in Figure 6. In this analogy, shear walls are represented as two line elements (centre line of shear wall), and beams are represented as line elements (centre line of beam) by joining with each other with rigid link. Beam column elastic element (Type-17) and inelastic element (Type-15) are considered for modeling.

3.6.4. Calculation of Ductility. The obtained design/capacity curve from the proposed design technique, SAP V 10.0.5 [23], and DRAIN-3DX [22] is bilinearized. The bilinear 


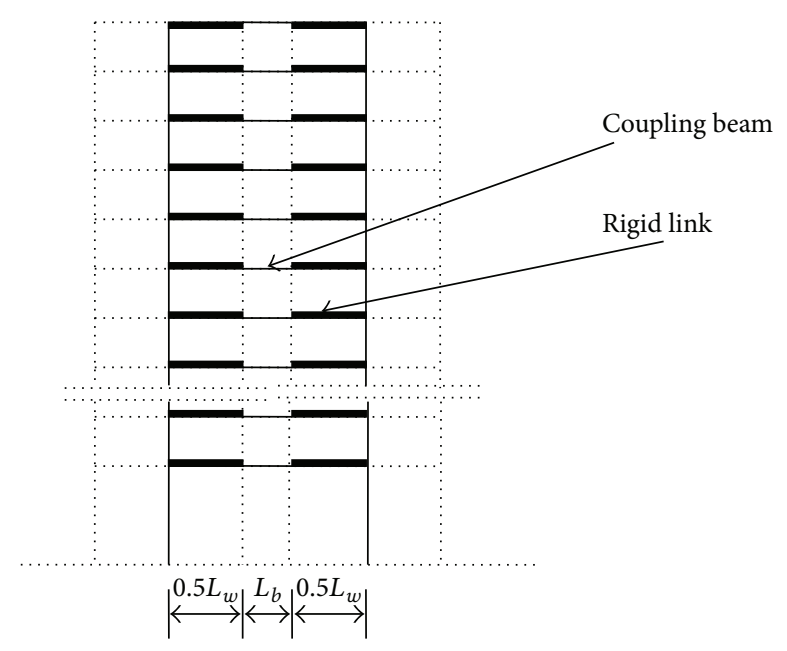

FIGURE 6: Modeling in SAP V 10.0.5 [23] and DRAIN-3DX [22].

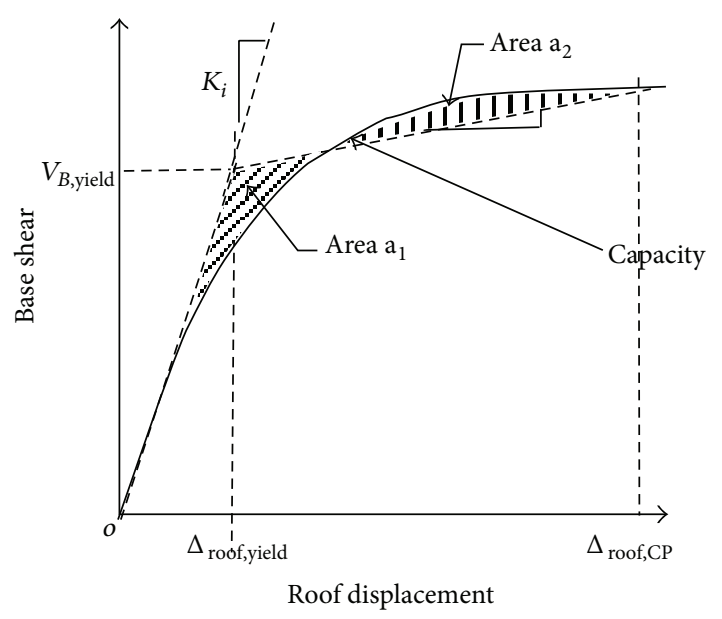

FIgURE 7: Bilinear representation for Capacity Curve.

representation is prepared in the manner shown in Figure 7 based on the concepts given in ATC 40 [16].

It can be seen from Figure 7 that bilinear representation can be due to the basis of initial tangent stiffness and equal energies (Area $a_{1}=$ Area $\left.a_{2}\right)$. Subsequently, ductility of the coupled shear walls has been calculated as

$$
\mu_{\Delta}=\frac{\Delta_{\text {roof,CP }}}{\Delta_{\text {roof,yield }}},
$$

where, $\Delta_{\text {roof,CP }}$ and $\Delta_{\text {roof,yield }}$ can be calculated from (24); $\mu_{\Delta}$ is the ductility which represents how much earthquake energy dissipates during an earthquake.

3.7. Results and Discussions. Coupled shear walls at section "a-a" as shown in Figure 5 are considered for conducting the study.

3.8. RCC Coupling Beam with Conventional Longitudinal Reinforcement and Conforming Transverse Reinforcement.
TABLE 14: Ductility of coupled shear walls considering different approaches.

\begin{tabular}{lcc}
\hline \multirow{2}{*}{ Method } & \multicolumn{2}{c}{ Ductility } \\
& Fixed base & Pinned base \\
\hline Proposed Design Technique & 7 & 7.5 \\
DRAIN-3DX [22] & 6.75 & 7.45 \\
SAP V 10.0.5 [23] & 6.92 & 7.47 \\
\hline
\end{tabular}

RCC coupling beam with Conventional longitudinal reinforcement and conforming transverse reinforcement in each storey has been selected as per Step 1 for the study. The results of this study for fixed base as well as pinned base conditions have been shown in Figure 8 and Table 14.

3.8.1. Discussions of Numerical Results. Figure 8(b) shows that the results obtained from proposed design technique for pinned base conditions are almost similar with the results obtained from DRAIN-3DX [22] and SAP V 10.0.5 [23]. Whereas, Figure 8(a) is showing a bit differences about the results obtained from proposed design technique, DRAIN3DX [22], and SAP V 10.0.5 [23] although same dimensions, same material properties, and same loading were considered in all the three techniques. However, the differences were not very high (5-10\%). Table 14 is showing the results about ductility obtained for fixed and pinned base conditions with the help of the Figures 8(a) and 8(b) and Section 3.6.4. It is noticed that ductility for pinned base condition is greater than fixed base conditions. It means that stable hysteresis with high earthquake energy dissipation can be obtained for coupled shear walls with pinned base.

The results obtained from the proposed design technique are satisfactory. However, it is necessary to find the limitations of the proposed design technique. Therefore, in the following section, parametric study is elaborately discussed to detect the limitations of the proposed design technique.

\section{Parametric Study}

It has been observed from the CSA [25] and Chaallal et al. [37] that the behavior of the ductile coupled shear walls depend on degree of coupling, where degree of coupling depends upon depth and length of the coupling beam as well as depth and height of the coupled shear walls $[4,10]$.

Therefore, this study has been restricted on length of the coupling beam and number of stories as basic variables and other parameters are considered as constant. These parameters have been considered in proposed method to make out effect on the behavior of coupled shear walls. Further, modifications to achieve ideal seismic behavior according to the proposed method have been included in this study.

4.1. Model for Parametric Study. A typical building with symmetrical coupled shear walls is shown in Figures 9(a) and 9(b). Coupled shear walls at section "a-a" have been considered to carry out the parametric study. 


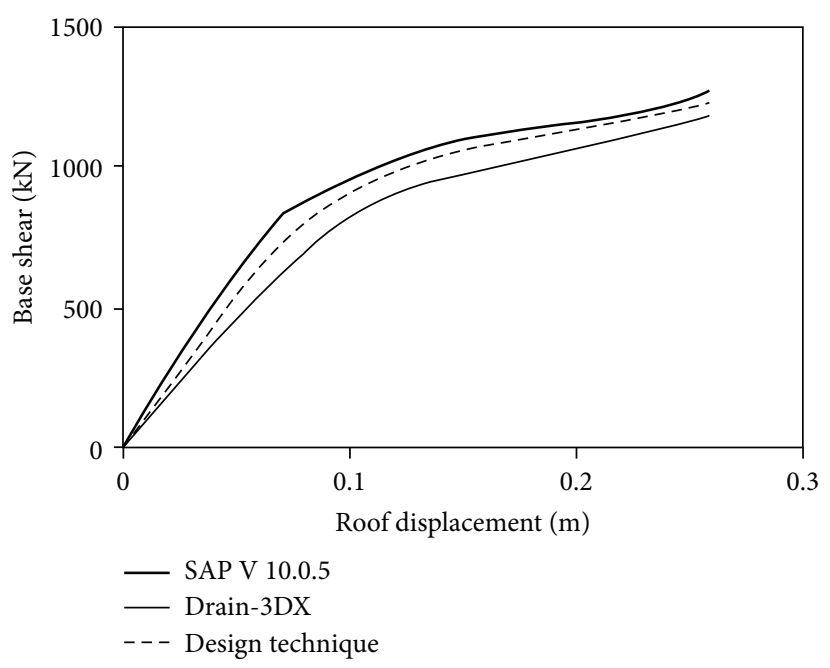

(a)

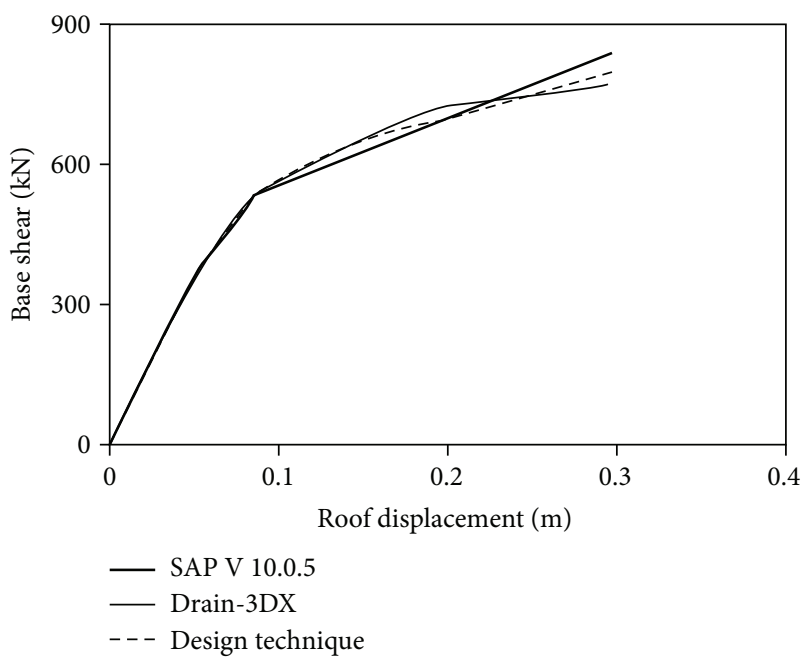

(b)

FIGURE 8: (a) Capacity curve for fixed base condition. (b) Capacity curve for pinned base condition.

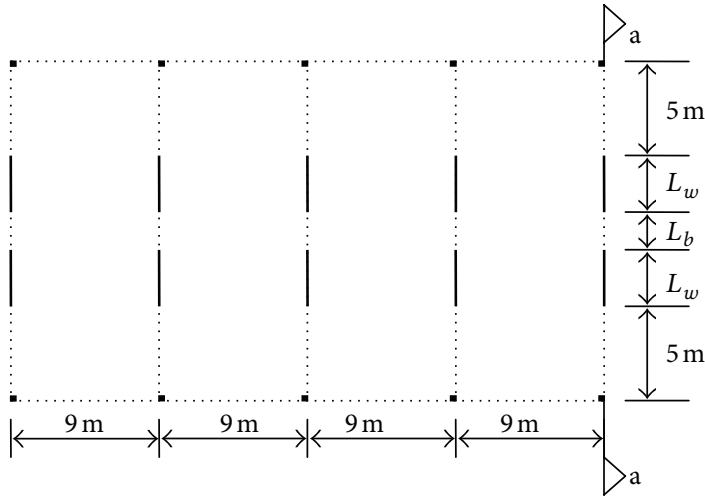

(a)

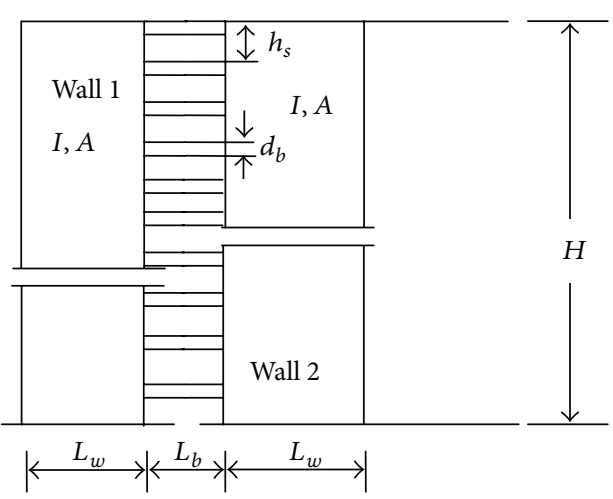

(b)

Figure 9: (a) Plan view of building with symmetrical coupled shear walls. (b) Coupled shear walls at section "a-a".

4.2. Loading Consideration. Dead loads (DL) of $6.7 \mathrm{kN} / \mathrm{m}^{2}$ and live loads (LL) of $2.4 \mathrm{kN} / \mathrm{m}^{2}$ have been considered as per the suggestions made by in Chaallal et al. [37]. Total gravity loading on coupled shear walls at section "a-a" has been calculated as the sum of dead load plus $25 \% \mathrm{LL}$ as per IS 1893 (part 1) [1] for floor; however, in case of roof only dead load is considered.

4.3. Parameters. Table 15 mentions the different parameters with dimensions and material properties which have been considered to carry out the parametric study.

4.4. Analysis Using Proposed Design Technique. The above men-tioned building has been studied by the design technique. The results for different parameters have been described in this section.

4.5. Observed Behavior. To study the influence of length of the coupling beam $\left(L_{b}\right)$ on the behavior of coupled shear walls, length of the coupling beam is considered as $1 \mathrm{~m}, 1.5 \mathrm{~m}$
TABLE 15: Dimensions and material properties of coupled shear walls for parametric study.

\begin{tabular}{lc}
\hline Depth of the wall $\left(L_{w}\right)$ & $4 \mathrm{~m}$ \\
Length of beam $\left(L_{b}\right)$ & $1 \mathrm{~m}, 1.5 \mathrm{~m}$ and $2 \mathrm{~m}$ \\
Depth of beam $\left(d_{b}\right)$ & $800 \mathrm{~mm}$ \\
Number of stories $(N)$ & $10,15 \mathrm{and} 20$ \\
Wall thickness $\left(t_{w}\right)$ & $300 \mathrm{~mm}$ \\
Width of coupling beam $\left(b_{b}\right)$ & $300 \mathrm{~mm}$ \\
Storey height $\left(h_{s}\right)$ & $3.6 \mathrm{~m}$ \\
Modulus of concrete $\left(E_{c}\right)$ & $22.4 \mathrm{GPa}$ \\
Yield strength of steel $\left(f_{y}\right)$ & $415 \mathrm{MPa}$ \\
\hline
\end{tabular}

and $2 \mathrm{~m}$ for both fixed and pinned base conditions. RCC coupling beam with conventional longitudinal reinforcement with conforming transverse reinforcement has been selected. Shear capacity in the coupling beam is calculated as per Step 1. The rotational limit of coupling beam has been selected as per Step 7. The study has been performed for coupled shear walls 
with number of stories 20,15, and 10 for both fixed and pinned base conditions.

4.5.1. For Number of Stories $N=20$. For more details, see Figures 10, 11, 12, and 13.

4.5.2. Discussion of Results for $N=20$. The deflection for the case of pinned base condition is much higher than the case of fixed base (Figure 10); however, the base shear for the case of pinned base condition is lower than the case of fixed base (Figure 13). It shows satisfactory results based on the behavior of coupled shear walls. Because, coupled shear walls with pinned base deflected more subjected to lesser lateral loading in comparison with the coupled shear walls with fixed base and base shear is directly varying with the lateral loading (26). Since wall rotation is directly varying with the length of the beam (Figure 11) and deflection is the summation of the wall rotation (25), deflection is directly varying with the length of the beam (Figure 10). It has been also observed that all beams reach to their rotational limit of CP level for pinned base condition; however, very few beams reach to their rotational limit of CP level for fixed base condition (Figure 12). Hence, it can be said that coupled shear walls are behaving as a rigid body motion for pinned base condition; which is expected. The explanations for fixed base condition (Figure 12) are given in the following manner:

(i) The rotation of the cantilever wall is maximum at the free end of the wall. This rotation decreases towards the base of the wall and is zero at the base for fixity.

(ii) Fixed base coupled shear walls with short span coupling beam is behaving as a cantilever wall $\left(L_{b}=\right.$ $1 \mathrm{~m}$ of Figure 11). It is also one of the behaviors of a coupled shear walls. However, fixed base coupled shear walls with long span coupling beam does not show cantilever wall $\left(L_{b}=1.5 \mathrm{~m}\right.$ and $L_{b}=2 \mathrm{~m}$ of Figure 11) behavior.

(iii) Beam rotation is proportional to the wall rotation.

Therefore, it can be said from the above observations that coupled shear walls with short span coupling beam $\left(L_{b}=\right.$ $1 \mathrm{~m}$ ) can be acceptable in comparison with the long span coupling beam $\left(L_{b}=1.5 \mathrm{~m}\right.$ and $\left.L_{b}=2 \mathrm{~m}\right)$ although the behavior of all three coupling beams is governed by shear according to Table 11.

With the help of Section 3.6.4 and Figure 13, ductility for pinned base condition and fixed base condition has been calculated in Table 16.

It has been observed from Table 16 that ductility is more for pinned base condition in comparison with the fixed base condition and ductility increases with increase in length of the coupling beam ((24) and (27), Figures 10, 11, and 13).

4.5.3. For Number of Stories $N=15$. For more details, see Figures 14, 15, 16, and 17.

4.5.4. Discussion of Results for $N=15$. With the help of Section 3.6.4 and Figure 17, ductility for pinned base condition and fixed base condition has been calculated in Table 17.
TABLE 16: Ductility of coupled shear walls for $N=20$.

\begin{tabular}{lcc}
\hline Base condition & Length of the coupling beam $\left(L_{b}\right)$ & Values \\
\hline \multirow{3}{*}{ Fixed } & $1 \mathrm{~m}$ & 3.33 \\
& $1.5 \mathrm{~m}$ & 4.8 \\
& $2 \mathrm{~m}$ & 6.3 \\
\hline \multirow{3}{*}{ Pinned } & $1 \mathrm{~m}$ & 5.11 \\
& $1.5 \mathrm{~m}$ & 6.35 \\
& $2 \mathrm{~m}$ & 7.1 \\
\hline
\end{tabular}

TABLE 17: Ductility of coupled shear walls for $N=15$.

\begin{tabular}{lcc}
\hline Base condition & Length of the coupling beam $\left(L_{b}\right)$ & Values \\
\hline \multirow{3}{*}{ Fixed } & $1 \mathrm{~m}$ & 2.93 \\
& $1.5 \mathrm{~m}$ & 4.0 \\
& $2 \mathrm{~m}$ & 5.9 \\
\hline \multirow{2}{*}{ Pinned } & $1 \mathrm{~m}$ & 4.5 \\
& $1.5 \mathrm{~m}$ & 5.85 \\
& $2 \mathrm{~m}$ & 6.87 \\
\hline
\end{tabular}

It has been observed from Figures 14 to 17 and Table 17 that the results obtained for $N=15$ are similar with the results of $N=20$ for fixed base condition and pinned base condition.

4.5.5. For Number of Stories $N=10$. For more details, see Figures 18, 19, 20, and 21.

4.5.6. Discussion of Results for $N=10$. Figures 20 and 21 show that beam rotation and capacity curve reach $\mathrm{CP}$ level for the case of $L_{b}=1 \mathrm{~m}$ with pinned base condition only. However, beam rotation and capacity curve do not reach the CP level for the other cases while shear capacities in all coupling beams have been achieved. It means that ideal seismic behavior (stable hysteresis with high earthquake energy dissipation) of coupled shear walls has only been achieved for $L_{b}=1 \mathrm{~m}$ with pinned base condition. Proposed design technique does not show ideal seismic behavior of coupled shear walls for $L_{b}=1 \mathrm{~m}, 1.5 \mathrm{~m}$ and $2 \mathrm{~m}$ with fixed base condition and $L_{b}=1.5 \mathrm{~m}$, and $2 \mathrm{~m}$ with pinned base condition. Now, remedial action has been considered in the following manner to obtain the ideal seismic behavior.

4.5.7. Remedial Action for $N=10$. The remedy for the cases of $L_{b}=1 \mathrm{~m}, 1.5 \mathrm{~m}$, and $2 \mathrm{~m}$ with fixed base condition and $L_{b}=1.5 \mathrm{~m}$ and $2 \mathrm{~m}$ with pinned base condition to achieve $\mathrm{CP}$ level is mentioned in (Figures 22, 23, 24 and 25). To obtain the CP level, it is required to increase the wall rotation. Since wall rotation $\left((18)\right.$ and (19)) is inversely varying to the $L_{w}^{3}$, it is required to decrease the $L_{w}$. It has been observed from Figure 25 that the ideal seismic behavior of coupled shear walls has been achieved.

4.5.8. Discussion of the Above Results. Figures 24 and 25 show that beam rotation and capacity curve reach CP level for all cases although the results are not satisfactory for 


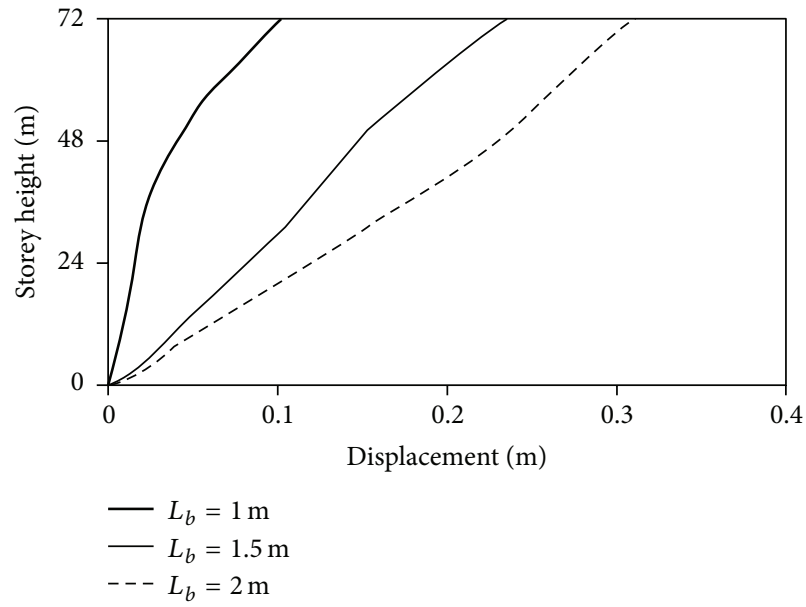

(a)

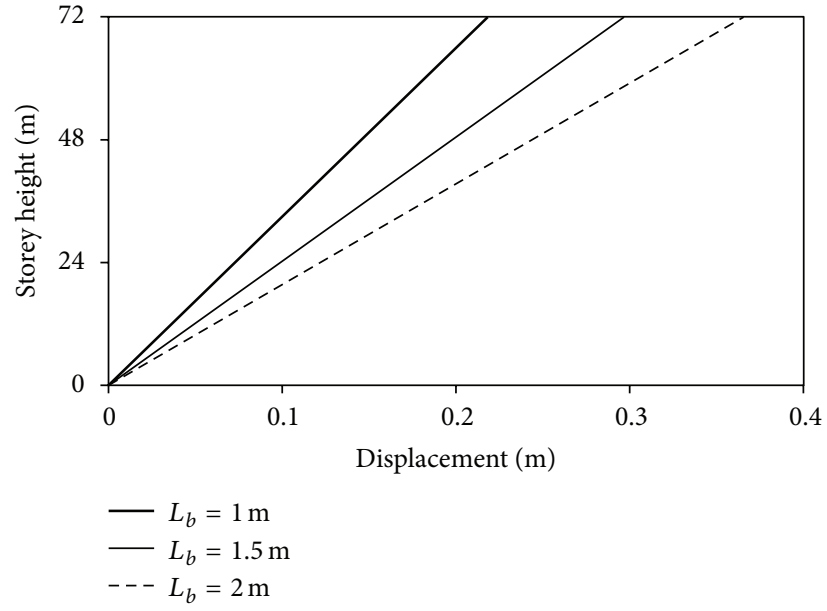

(b)

Figure 10: (a) Storey displacement for fixed base condition at CP level. (b) Storey displacement for pinned base condition at CP level.

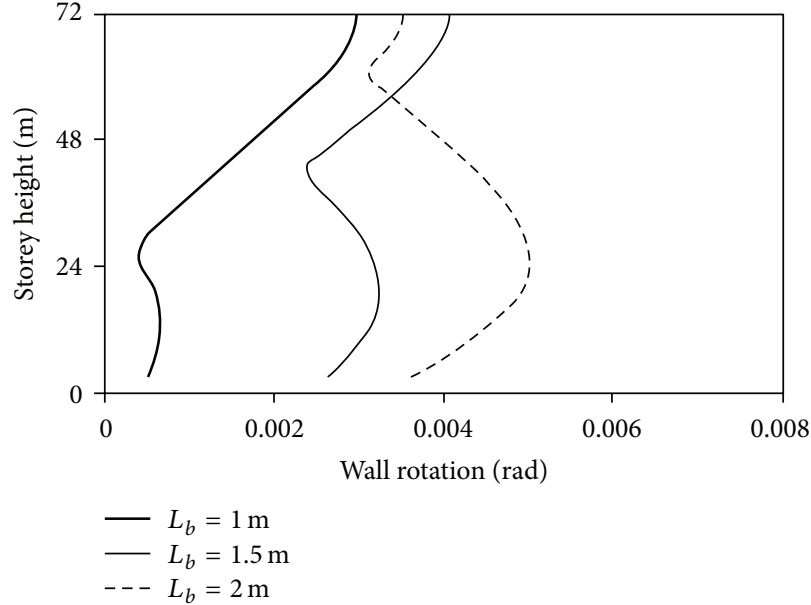

(a)

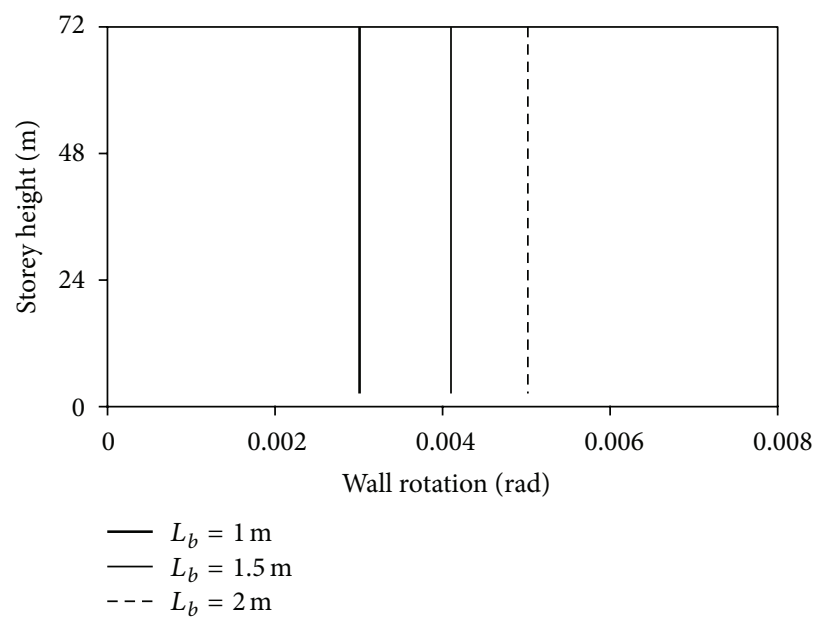

(b)

FIgURE 11: (a) Wall rotation for fixed base condition at CP level. (b) Wall rotation for pinned base condition at CP level.
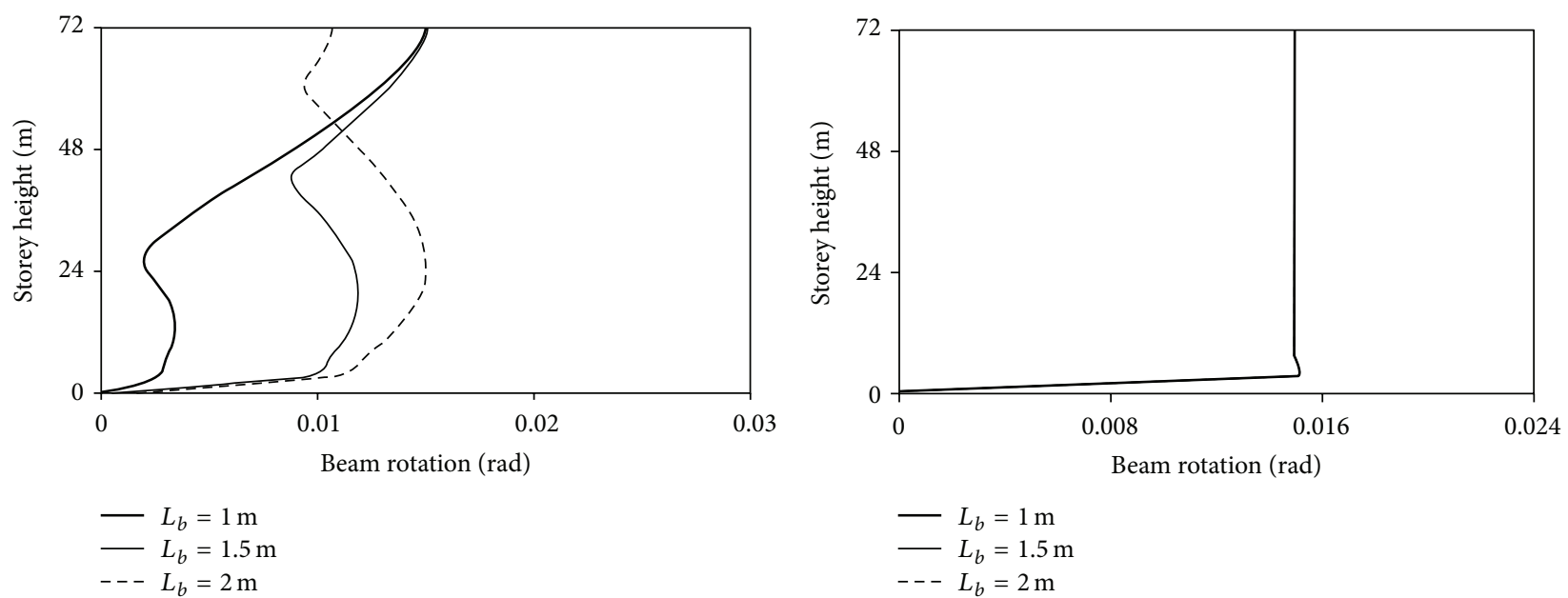

(a)

(b)

Figure 12: (a) Beam rotation for fixed base condition at CP level. (b) Beam rotation for pinned base condition at CP level. 


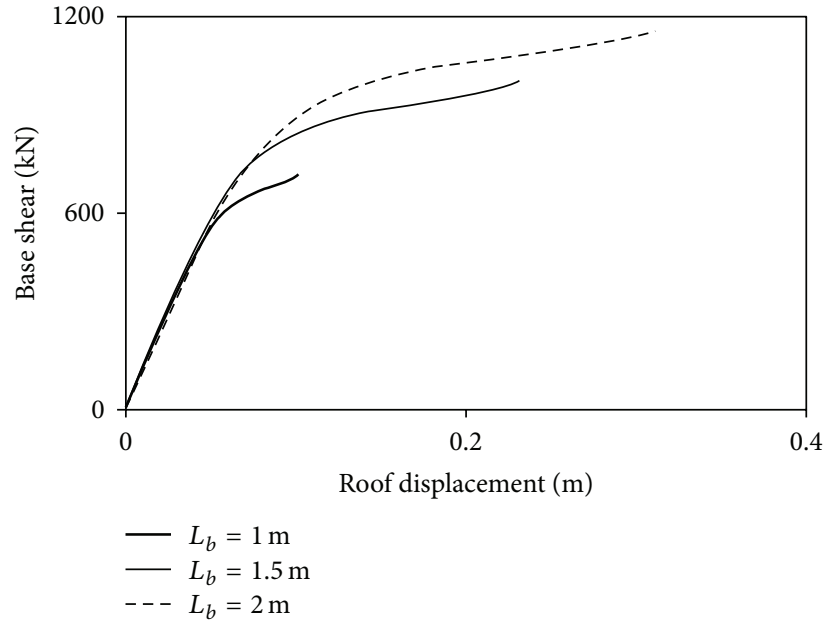

(a)

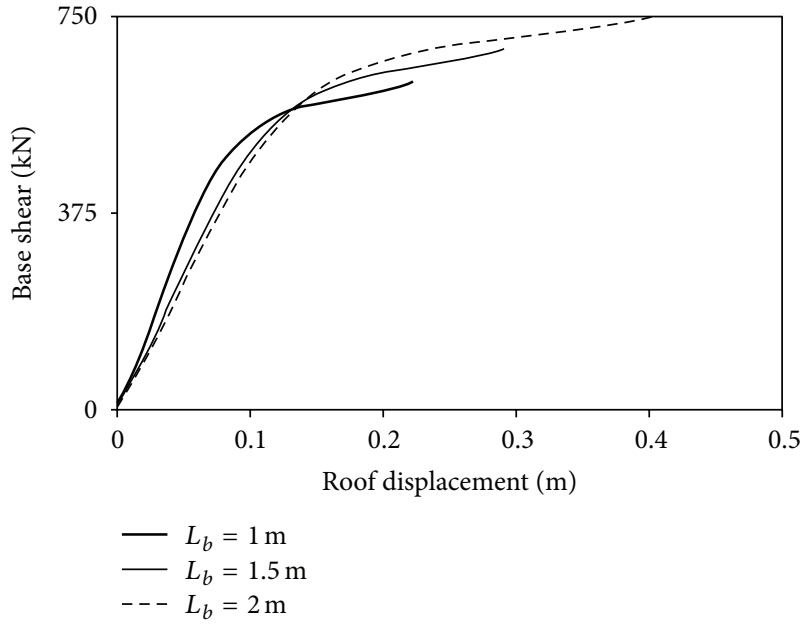

(b)

Figure 13: (a) Capacity curve for fixed base condition. (b) Capacity curve for pinned base condition.
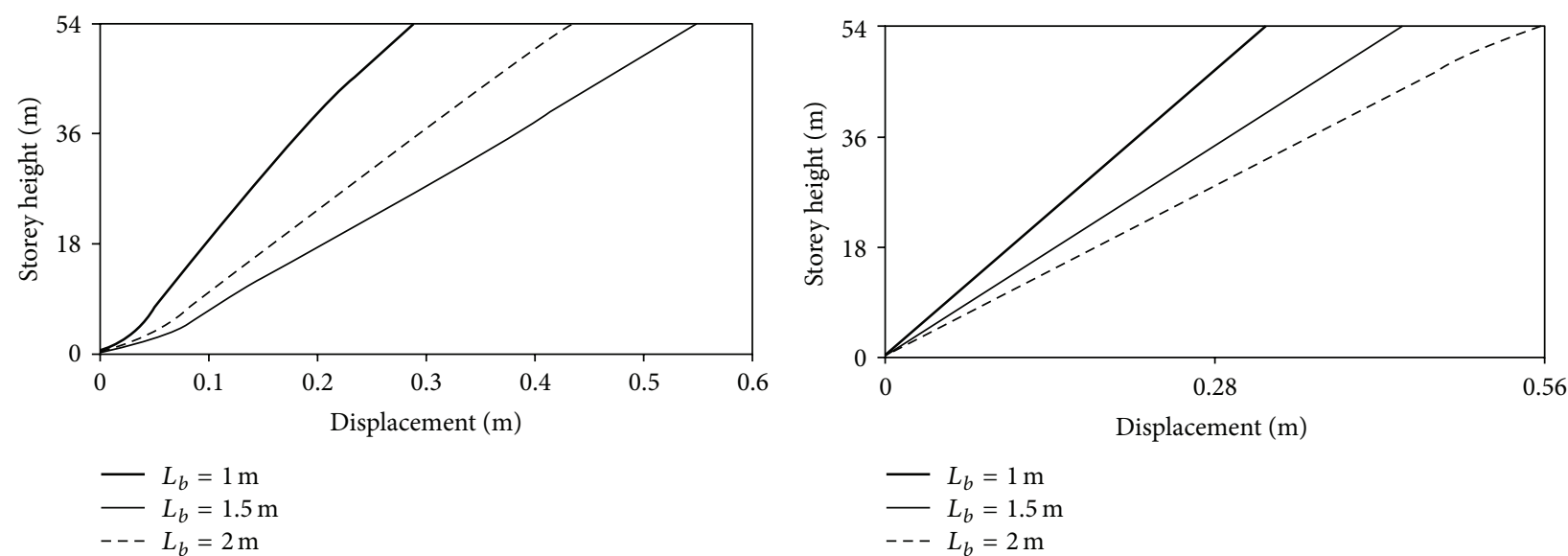

(a)

(b)

FIGURE 14: (a) Storey displacement for fixed base condition at CP level. (b) Storey displacement for pinned base condition at CP level.
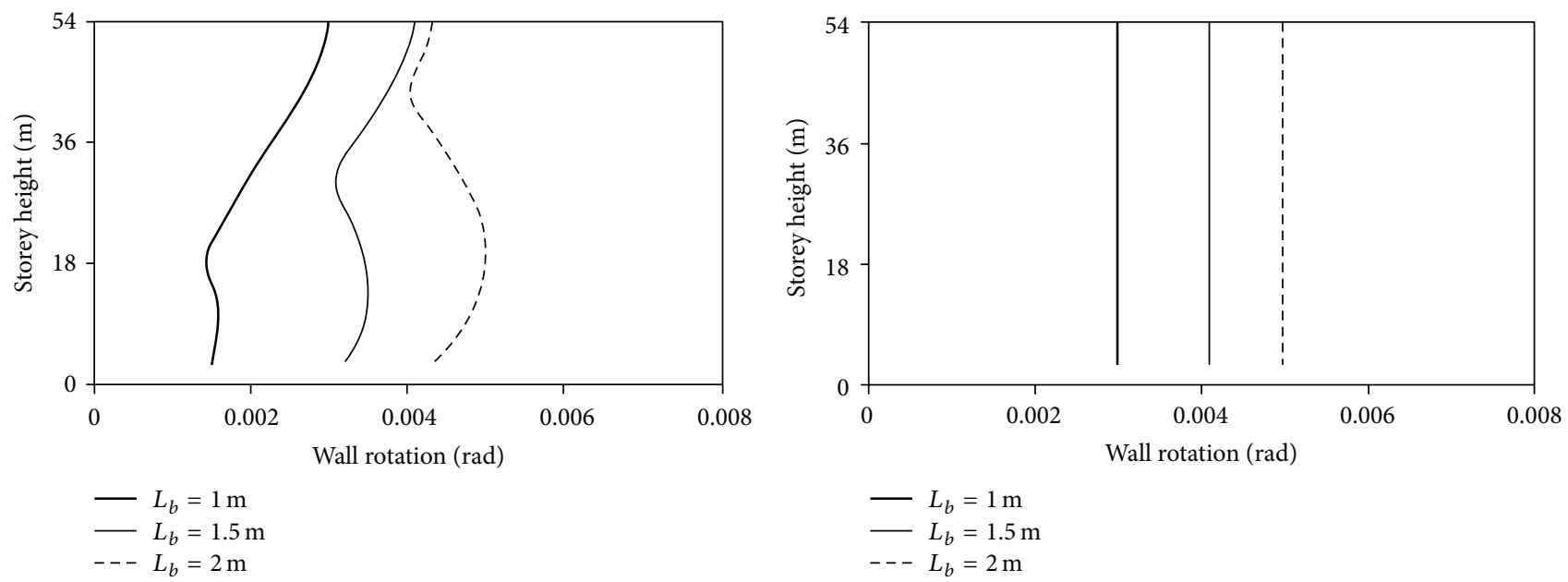

(a)

(b)

FIGURE 15: (a) Wall rotation for fixed base condition at CP level. (b) Wall rotation for pinned base condition at CP level. 

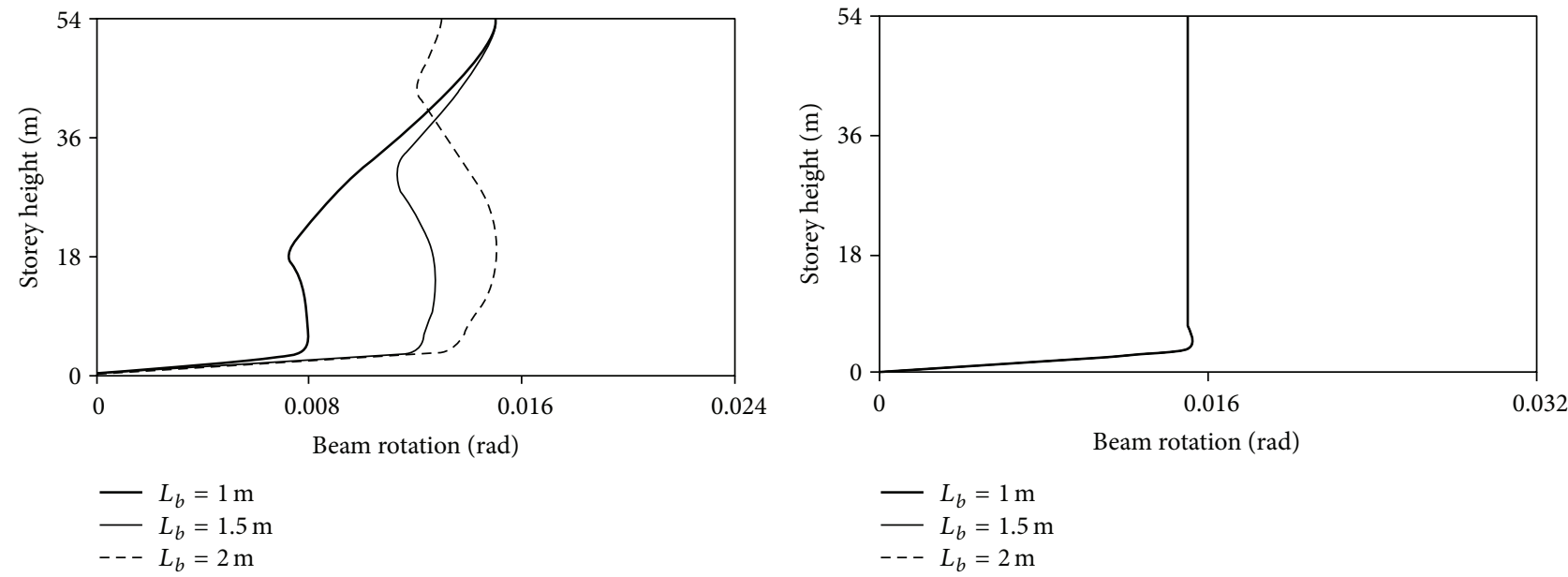

(a)

(b)

Figure 16: (a) Beam rotation for fixed base condition at CP level. (b) Beam rotation for pinned base condition at CP level.
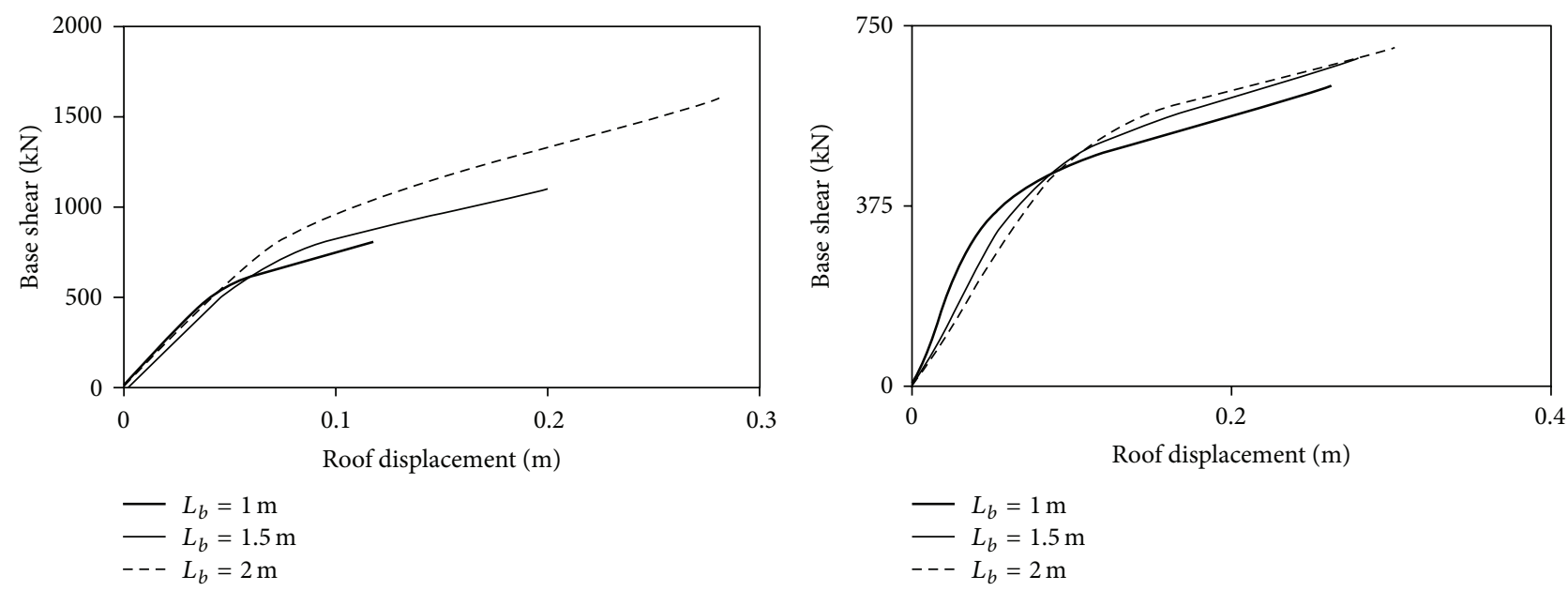

(a)

(b)

FIGURE 17: (a) Capacity curve for fixed base condition. (b) Capacity curve for pinned base condition.

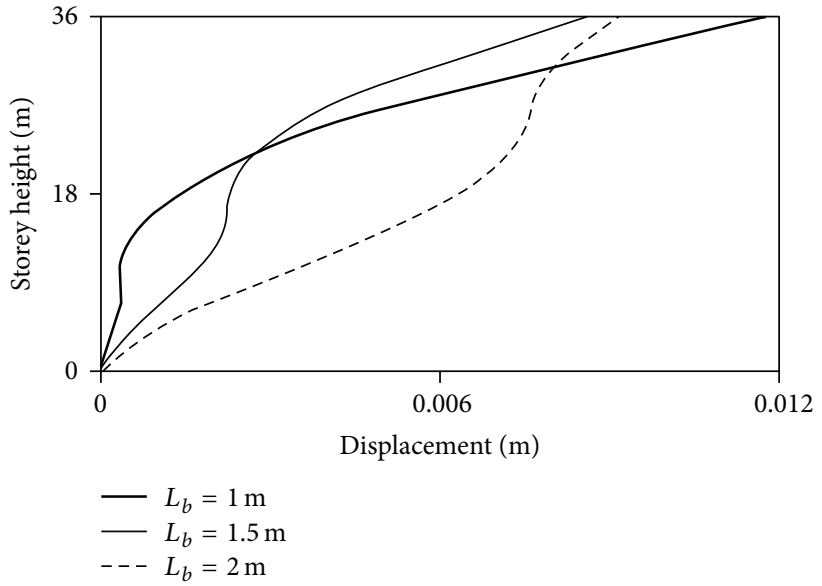

(a)

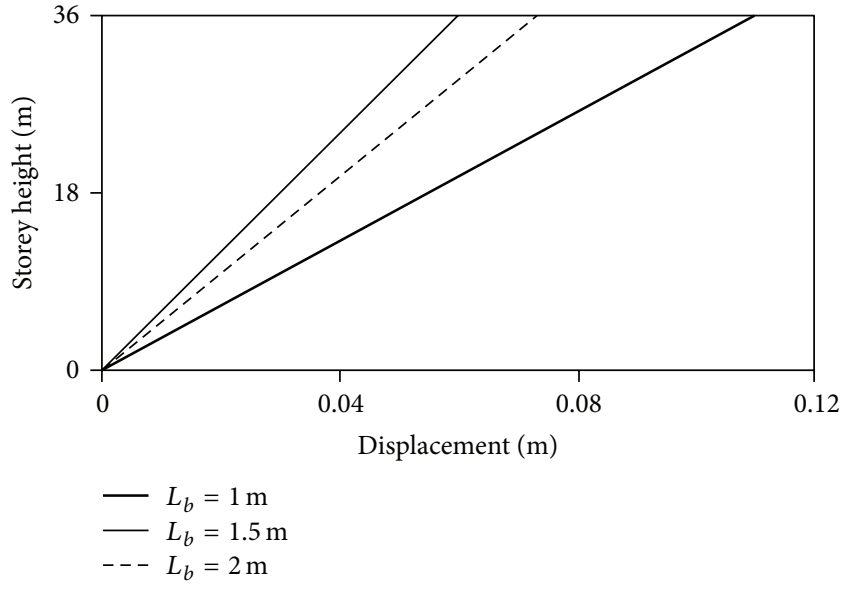

(b)

Figure 18: (a) Storey displacement for fixed base condition at CP level. (b) Storey displacement for pinned base condition at CP level. 

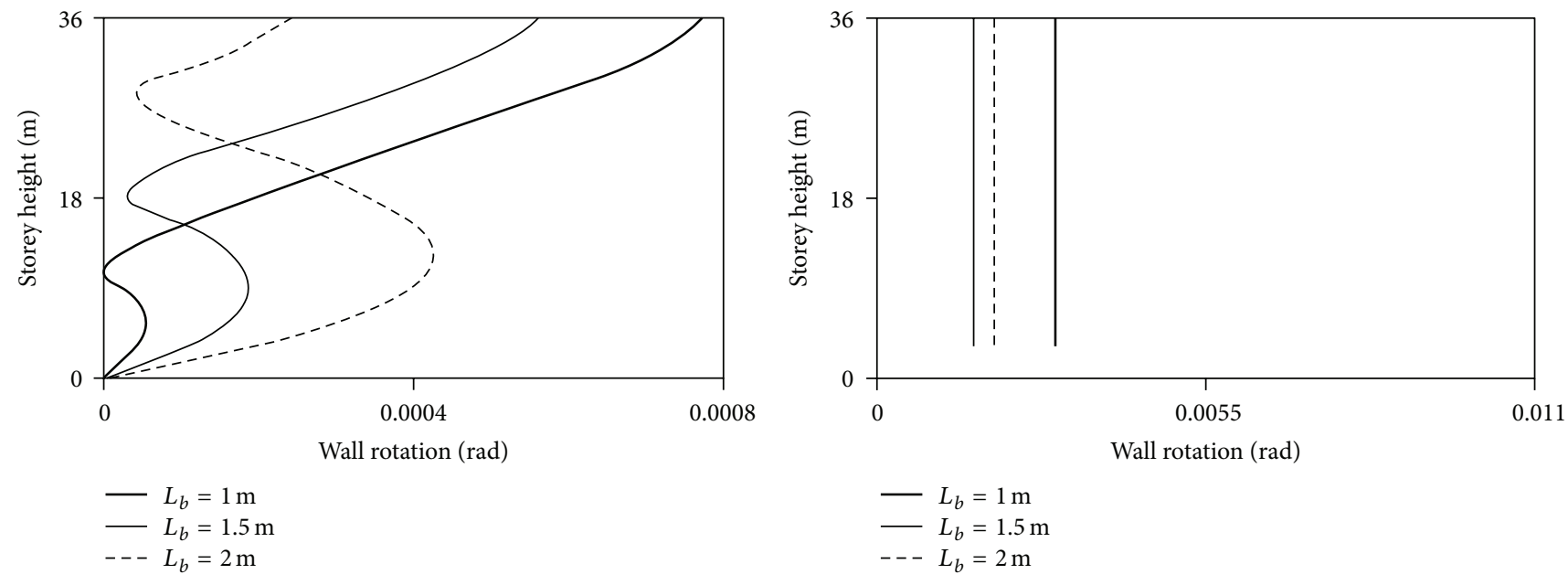

(a)

(b)

FIGURE 19: (a) Wall rotation for fixed base condition at CP level. (b) Wall rotation for pinned base condition at CP level.
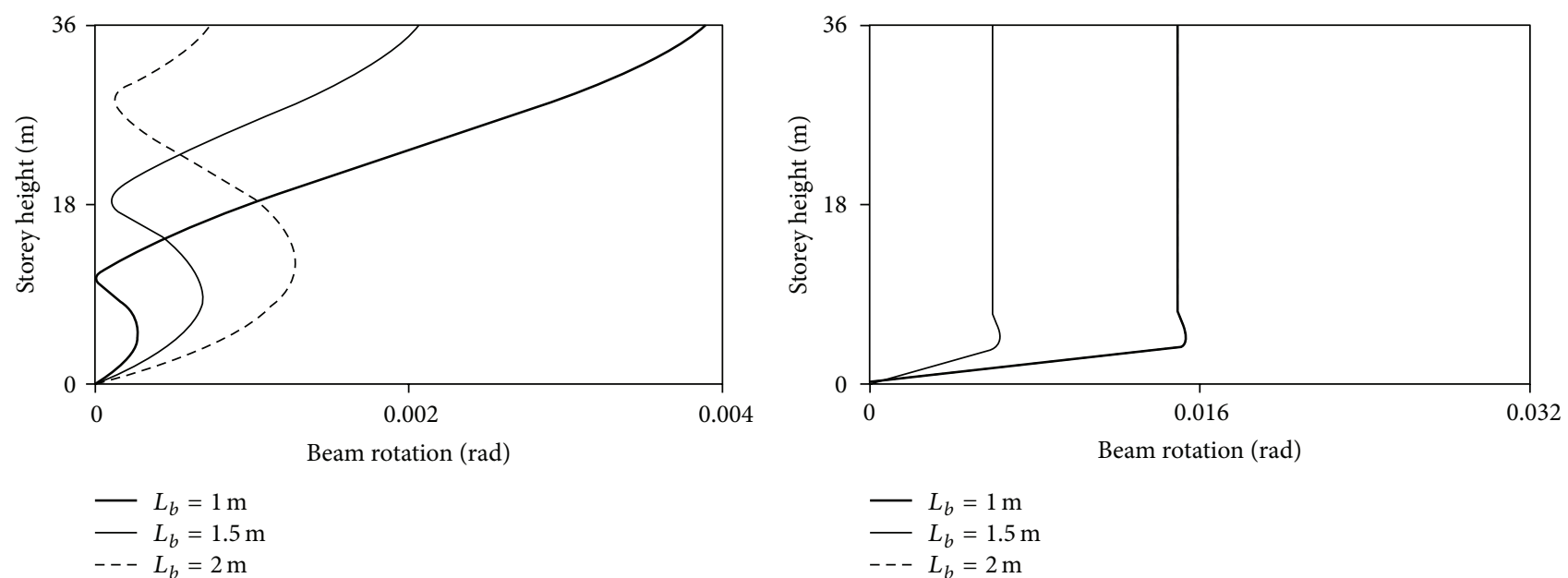

(a)

(b)

FIgURE 20: (a) Beam rotation for fixed base condition at CP level. (b) Beam rotation for pinned base condition at CP level.

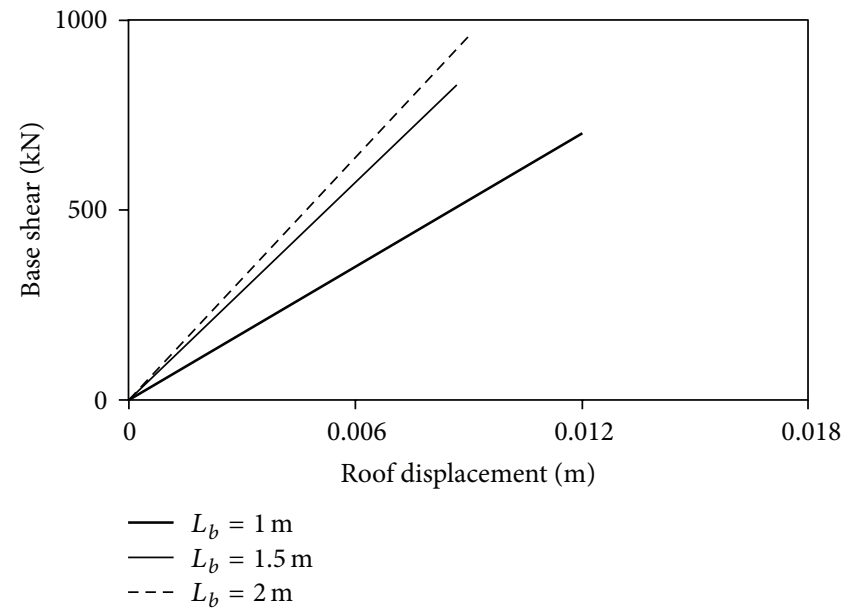

(a)

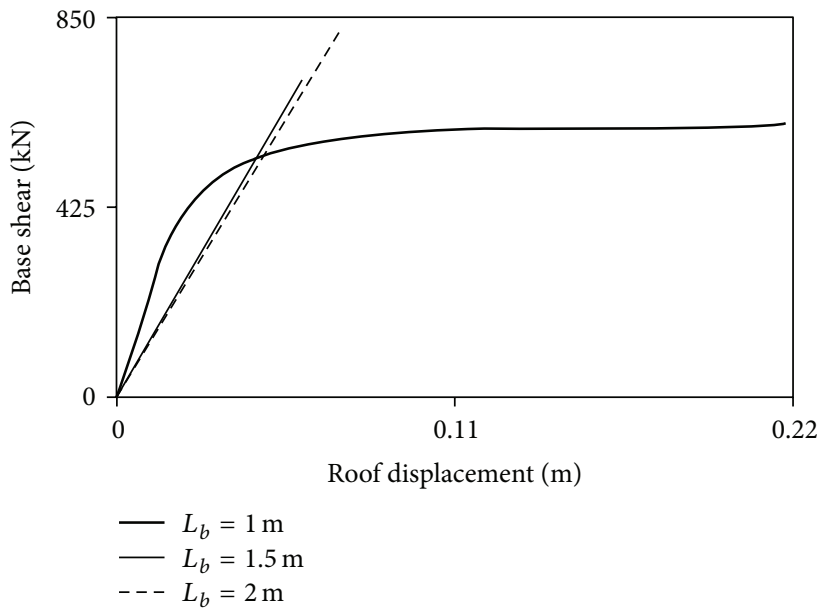

(b)

FIgURE 21: (a) Capacity curve for fixed base condition. (b) Capacity curve for pinned base condition. 


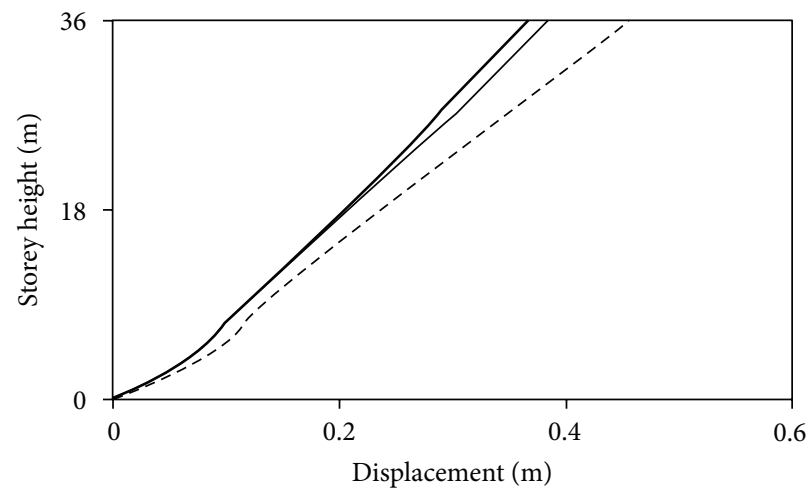

$\begin{aligned}- & L_{b}=1 \mathrm{~m} \text { and } L_{w}=2 \mathrm{~m} \text { for fixed and } 4 \mathrm{~m} \text { for pinned } \\ - & L_{b}=1.5 \mathrm{~m} \text { and } L_{w}=3 \mathrm{~m} \\ ---L_{b} & =2 \mathrm{~m} \text { and } L_{w}=3 \mathrm{~m}\end{aligned}$

(a)

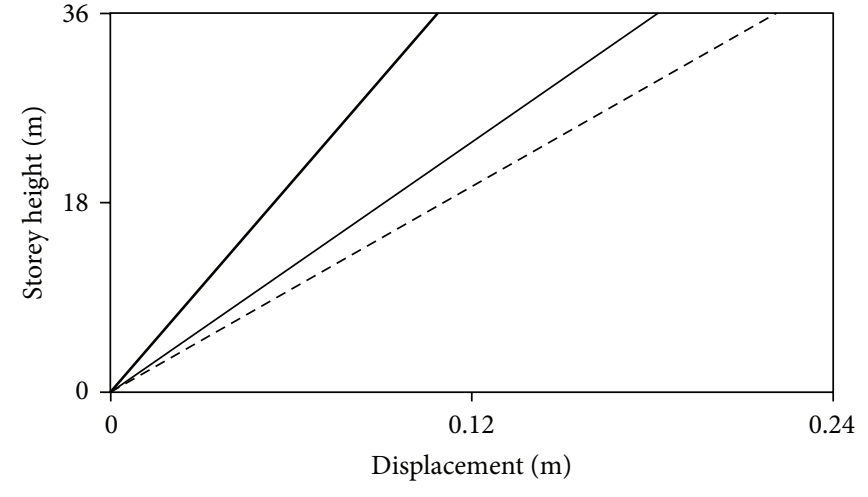

$$
\begin{aligned}
-L_{b} & =1 \mathrm{~m} \text { and } L_{w}=2 \mathrm{~m} \text { for fixed and } 4 \mathrm{~m} \text { for pinned } \\
-L_{b} & =1.5 \mathrm{~m} \text { and } L_{w}=3 \mathrm{~m} \\
--- & L_{b}=2 \mathrm{~m} \text { and } L_{w}=3 \mathrm{~m}
\end{aligned}
$$

(b)

FIGURE 22: (a) Storey displacement for fixed base condition at CP level. (b) Storey displacement for pinned base condition at CP level.

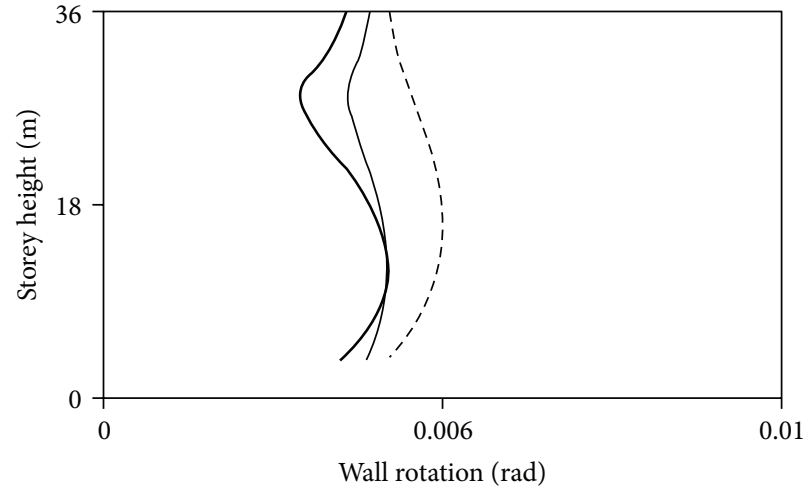

- $L_{b}=1 \mathrm{~m}$ and $L_{w}=2 \mathrm{~m}$ for fixed and $4 \mathrm{~m}$ for pinned

$-L_{b}=1.5 \mathrm{~m}$ and $L_{w}=3 \mathrm{~m}$

$--L_{b}=2 \mathrm{~m}$ and $L_{w}=3 \mathrm{~m}$

(a)

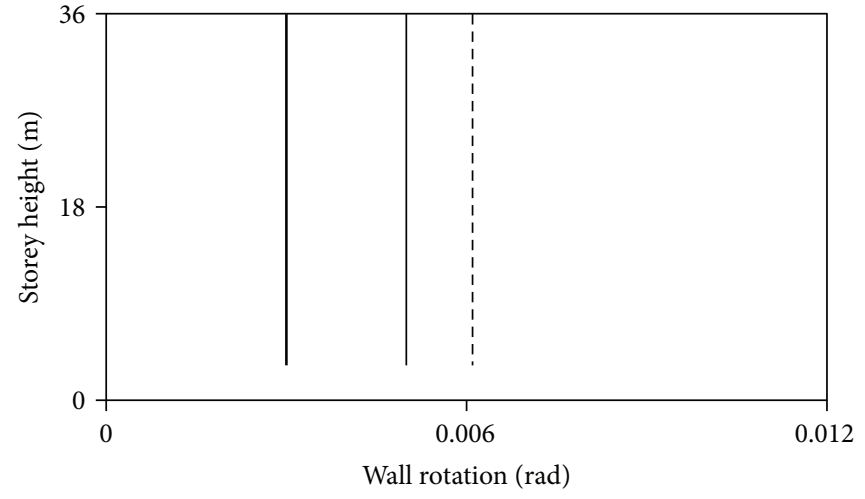

- $L_{b}=1 \mathrm{~m}$ and $L_{w}=2 \mathrm{~m}$ for fixed and $4 \mathrm{~m}$ for pinned - $L_{b}=1.5 \mathrm{~m}$ and $L_{w}=3 \mathrm{~m}$

$--L_{b}=2 \mathrm{~m}$ and $L_{w}=3 \mathrm{~m}$

(b)

FIgURE 23: (a) Wall rotation for fixed base condition at CP level. (b) Wall rotation for pinned base condition at CP level.

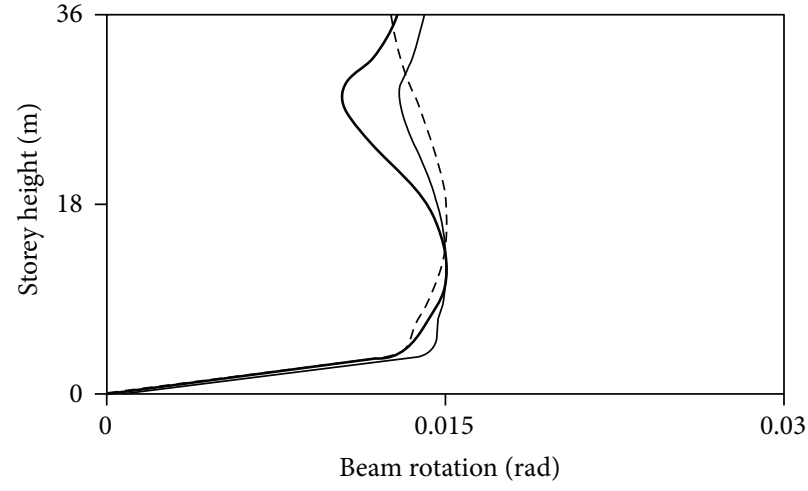

- $L_{b}=1 \mathrm{~m}$ and $L_{w}=2 \mathrm{~m}$ for fixed and $4 \mathrm{~m}$ for pinned - $L_{b}=1.5 \mathrm{~m}$ and $L_{w}=3 \mathrm{~m}$

$--L_{b}=2 \mathrm{~m}$ and $L_{w}=3 \mathrm{~m}$

(a)

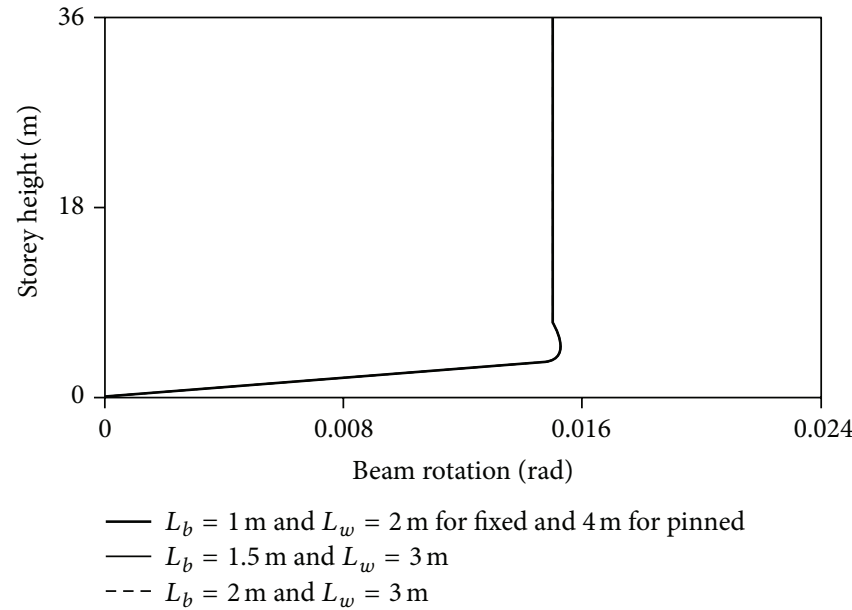

(b)

FIgure 24: (a) Beam rotation for fixed base condition at CP level. (b) Beam rotation for pinned base condition at CP level. 


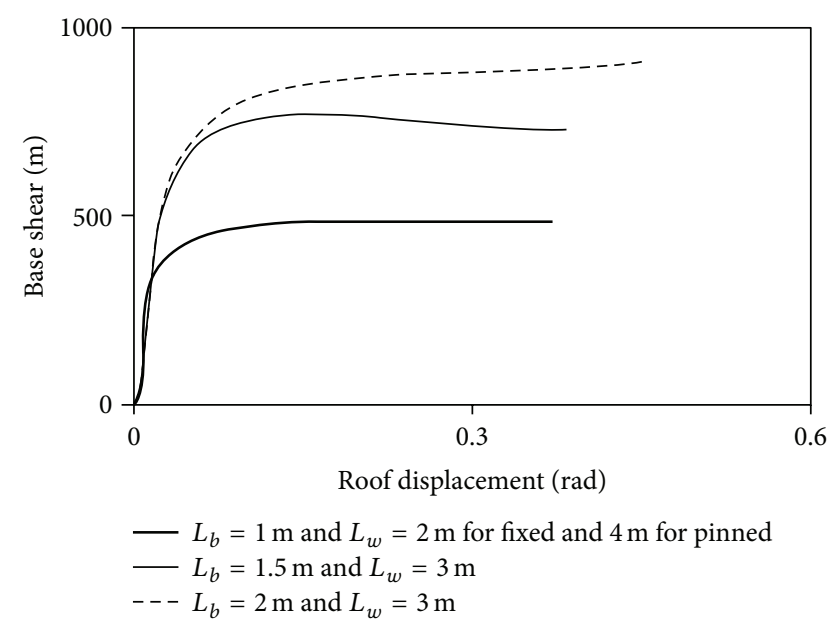

(a)

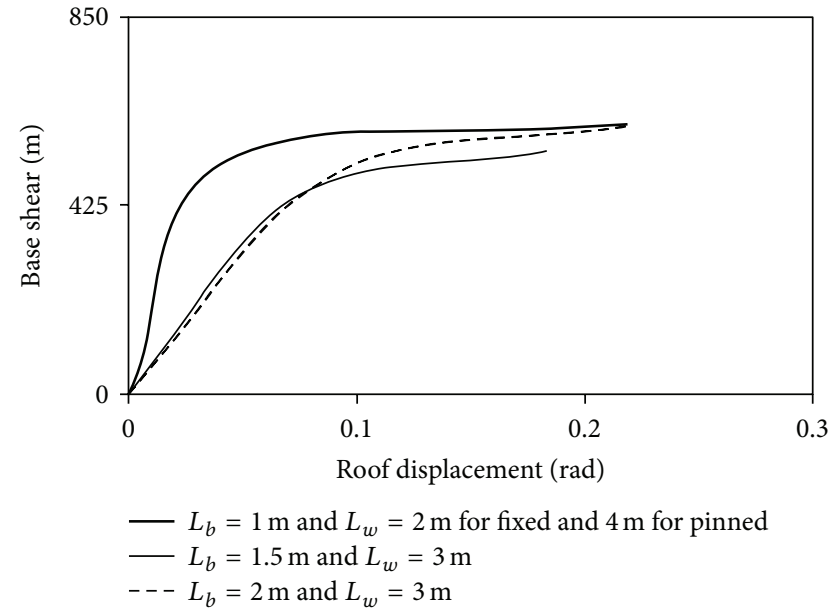

(b)

Figure 25: (a) Capacity curve for fixed base condition. (b) Capacity curve for pinned base condition.

TABLE 18: Dimensions and material properties of coupled shear walls for nonlinear static analysis.

\begin{tabular}{lc}
\hline Depth of the wall $\left(L_{w}\right)$ & $4 \mathrm{~m}$ \\
Length of beam $\left(L_{b}\right)$ & $1 \mathrm{~m}$ \\
Depth of beam $\left(d_{b}\right)$ & $800 \mathrm{~mm}$ \\
Number of stories $(N)$ & 20 and 15 \\
Wall thickness $\left(t_{w}\right)$ & $300 \mathrm{~mm}$ \\
Width of coupling beam $\left(b_{b}\right)$ & $300 \mathrm{~mm}$ \\
Storey height $\left(h_{s}\right)$ & $3.6 \mathrm{~m}$ \\
Modulus of concrete $\left(E_{c}\right)$ & $22.4 \mathrm{GPa}$ \\
Modulus of steel $\left(E_{s}\right)$ & $200.0 \mathrm{GPa}$ \\
Steel yield strength $\left(f_{y}\right)$ & $415 \mathrm{MPa}$ \\
\hline
\end{tabular}

fixed base condition according to the explanations given in Section 4.5.1.

Hence, it can be said from the above results that proposed design technique is useful to design the coupled shear walls during earthquake motion. To confirm it more, nonlinear static analysis is considered in the following manner to assess the proposed design technique.

\section{Assessment of Proposed Design Technique Using Nonlinear Static Analysis}

In this paper, nonlinear static analysis is carried out to determine the response reduction factors of coupled shear walls at different earthquake levels.

5.1. Design Example. The following design example is presented for carrying out the nonlinear static analysis of coupled shear walls. These walls are subjected to triangular variation of lateral loading. The base of the walls is assumed as fixed. Table 18 mentions the different parameters with dimensions and material properties which have been considered to carry out the study. Figures 26(a) and 26(b) show the plan and sectional elevation of the coupled shear wall building, respectively. The place considered for this study is Roorkee and soil type for this place is medium (Type II); maximum considered earthquake (MCE) level and design basis earthquake level (DBE) are considered for the study.

5.2. Loading Consideration. Dead loads (DL) of $6.7 \mathrm{kN} / \mathrm{m}^{2}$ and live loads (LL) of $2.4 \mathrm{kN} / \mathrm{m}^{2}$ have been considered as given in Chaallal et al. [37]. Total gravity loading on coupled shear walls at section "a-a" has been calculated as the sum of dead load plus 25\% LL as per IS 1893 (part 1) [1] for floor; however, in case of roof only dead load is considered.

5.3. Results and Discussions. The results and discussions are described in Figure 27.

5.3.1. Calculation of Performance Point. Place considered here is Roorkee which belongs to the seismic zone IV and $\mathrm{Z}$ is 0.24 as per IS 1893 (part 1) [1]. 5\% damped elastic response spectra as per IS 1893 (part 1) [1] are considered here as demand curve. DBE and MCE levels are considered for calculation of performance point (pp). Capacity curves are already obtained in Figure 27. The performance point has been calculated with the help of capacity spectrum method of ATC 40 [16] which is shown in Figure 28.

In this case, modal mass co-efficient $\alpha_{1}=0.616$ and Mode participation factor $\mathrm{PF}_{1}=1.51$ derived with the help of modal analysis in SAP V 10.0.5 [23]. Figure 28 shows that pp is the performance point. The base shear at the performance point (pp), $V_{\mathrm{b}, \mathrm{pp}}=1173.1 \mathrm{kN}$ and roof displacement at the performance point (pp), $\Delta_{\text {roof,pp }}=0.31 \mathrm{~m}$.

In this case, modal mass co-efficient $\alpha_{1}=0.616$ and Mode participation factor $\mathrm{PF}_{1}=1.51$. Figure 29 shows that $\mathrm{pp}$ is the performance point. The base shear at the performance point (pp), $V_{\mathrm{b}, \mathrm{pp}}=957.6 \mathrm{kN}$ and roof displacement at the performance point (pp), $\Delta_{\text {roof,pp }}=0.097 \mathrm{~m}$. 


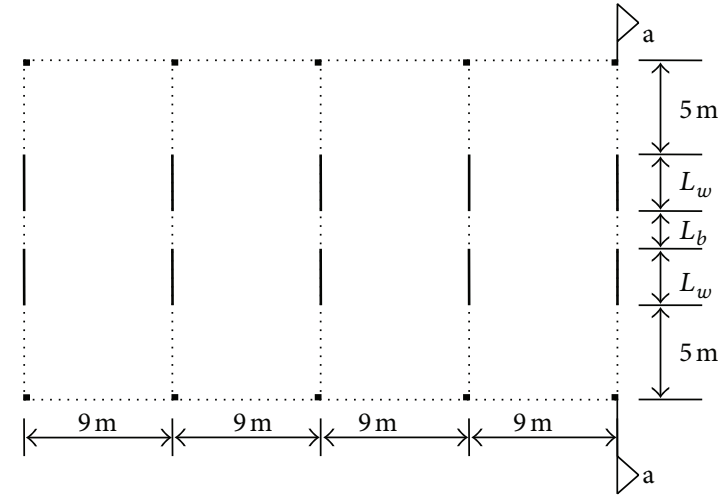

(a)

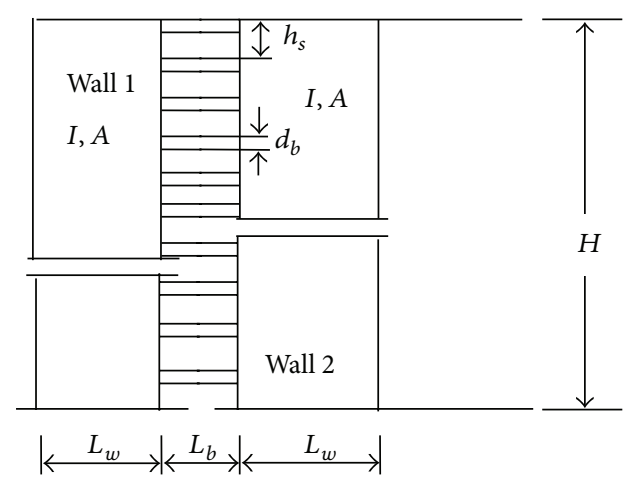

(b)

Figure 26: (a) Plan view of building with coupled shear walls. (b) Coupled shear walls at section "a-a".

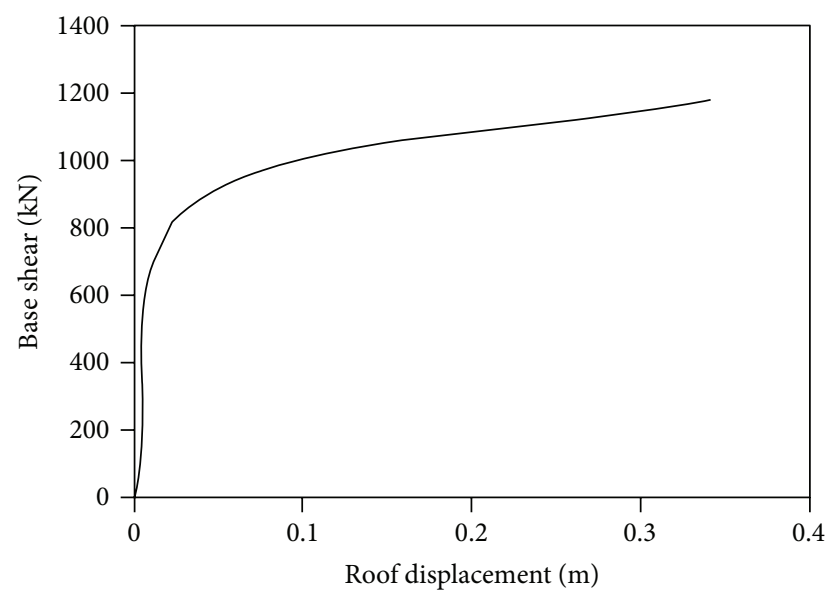

(a)

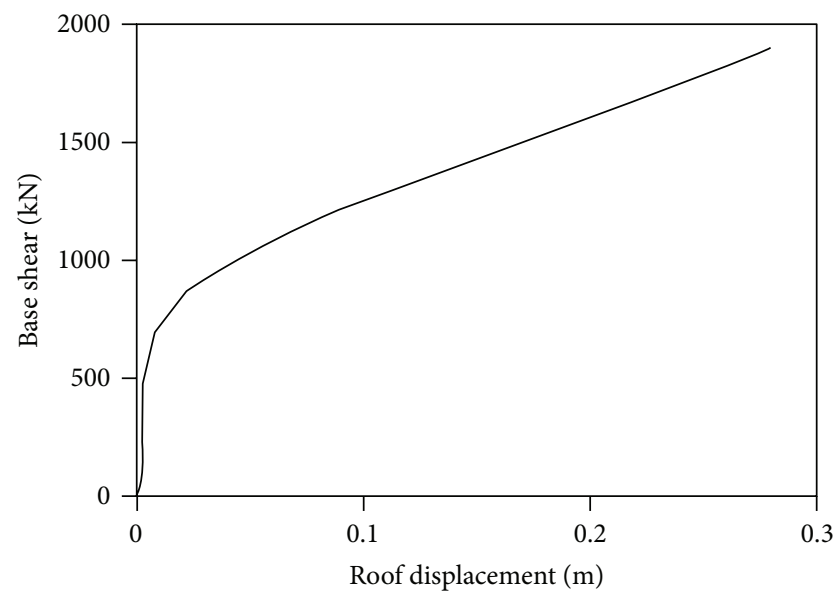

(b)

Figure 27: (a) Capacity curve for $N=20$. (b) Capacity curve for $N=15$.

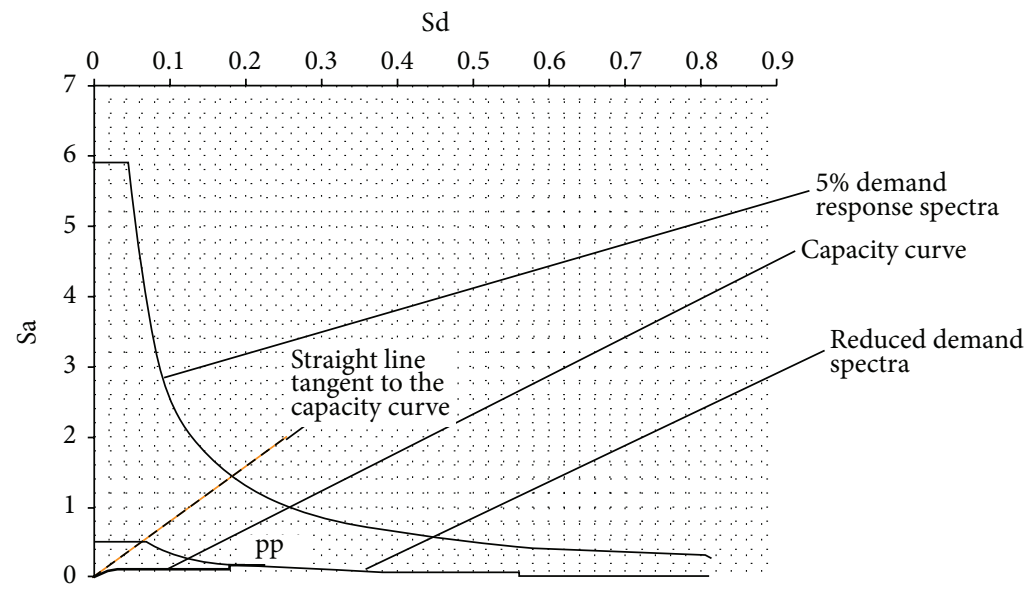

FIGURE 28: Performance point at the MCE level for $N=20$. 


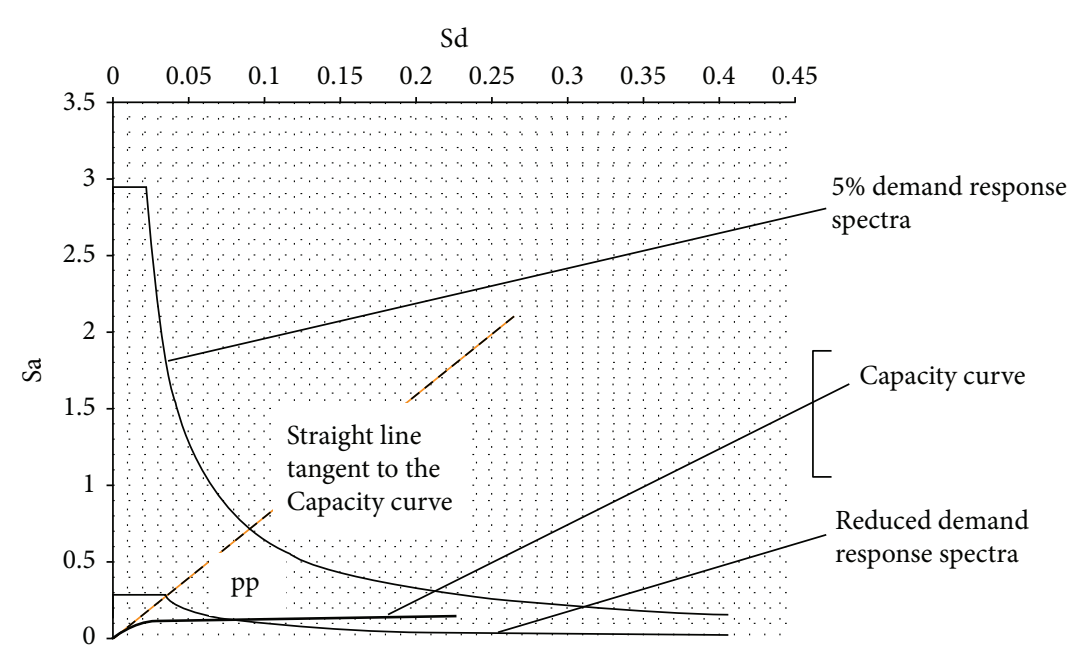

FIgURE 29: Performance point at the DBE level for $N=20$.

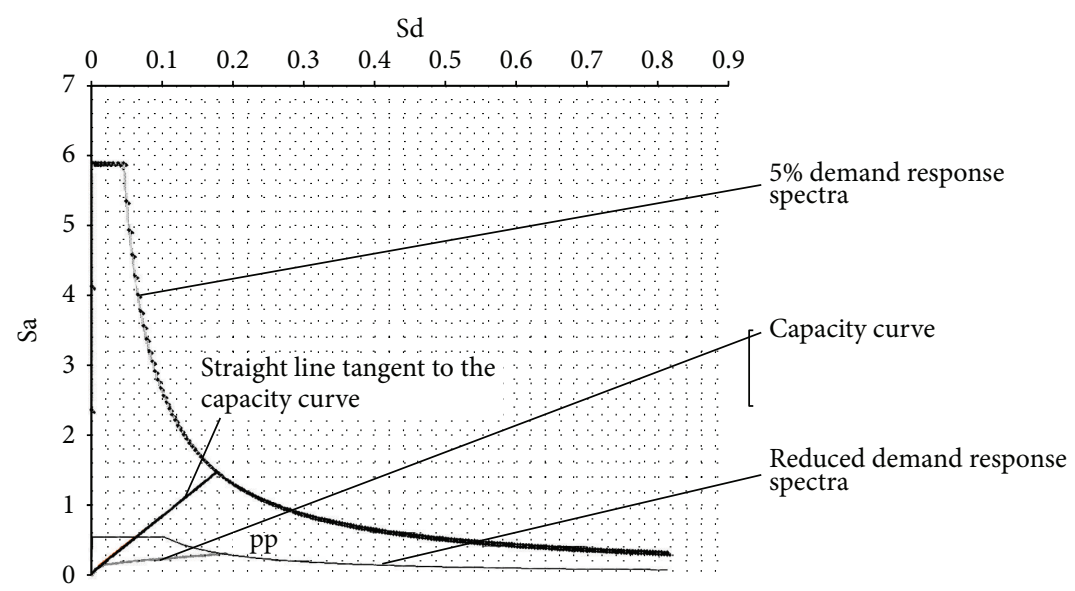

Figure 30: Performance point at the MCE level for $N=15$.

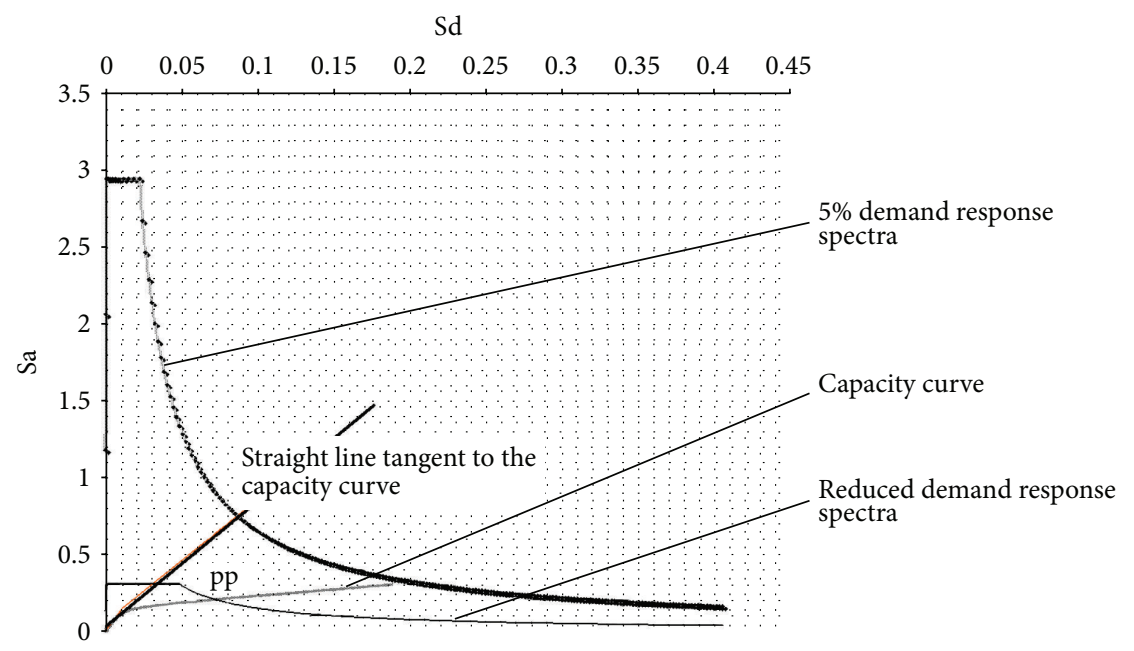

FIgURE 31: Performance point at the DBE level for $N=15$. 
TABLE 19: Response Reduction Factors for DBE and MCE levels.

\begin{tabular}{|c|c|c|c|c|c|c|c|}
\hline \multicolumn{2}{|c|}{ Parameters } & \multirow{3}{*}{$\begin{array}{c}\mu_{\Delta e 1}[24] \\
1.04\end{array}$} & \multirow{3}{*}{$\begin{array}{c}\mu_{\Delta e 2}[24] \\
1.004\end{array}$} & \multirow{3}{*}{$\begin{array}{c}R_{\mu \xi}[24] \\
1.02\end{array}$} & \multirow{3}{*}{$\begin{array}{c}R_{\mu \mathrm{IDRS}}[\text { First } \\
\text { method of } \\
\text { Energy-Ductility } \\
\text { Based Response } \\
\text { Reduction] [24] }\end{array}$} & \multirow{3}{*}{$\begin{array}{c}R_{\mu \mathrm{IDRS}}[\text { Second } \\
\text { method of } \\
\text { Energy-Ductility } \\
\text { Based Response } \\
\text { Reduction] [24] }\end{array}$} & \multirow{2}{*}{$\begin{array}{c}R_{d} \text { as per CSA } \\
{[25]}\end{array}$} \\
\hline \multirow{3}{*}{$N=20$} & & & & & & & \\
\hline & DBE & & & & & & \multirow{4}{*}{$\begin{array}{l}\text { l.5 or } 2 \text { for coupled } \\
\text { shear walls with } \\
\text { conventional } \\
\text { reinforced coupling } \\
\text { beam }\end{array}$} \\
\hline & MCE & 2.05 & 1.2 & 1.58 & 2.05 & 1.34 & \\
\hline \multirow[t]{2}{*}{$N=15$} & DBE & 1.01 & 1.00 & 1.002 & 1.01 & 1.00 & \\
\hline & MCE & 1.87 & 1.13 & 1.39 & 1.87 & 1.22 & \\
\hline
\end{tabular}

In this case, modal mass co-efficient $\alpha_{1}=0.644$ and Mode participation factor $\mathrm{PF}_{1}=1.485$. Figure 30 shows that $\mathrm{pp}$ is the performance point. The base shear at the performance point (pp), $V_{\mathrm{b}, \mathrm{pp}}=1455.3 \mathrm{kN}$ and roof displacement at the performance point (pp), $\Delta_{\text {roof,pp }}=0.259 \mathrm{~m}$.

In this case, modal mass co-efficient $\alpha_{1}=0.644$ and Mode participation factor $\mathrm{PF}_{1}=1.485$. Figure 31 shows that $\mathrm{pp}$ is the performance point. The base shear at the performance point (pp), $V_{\mathrm{b}, \mathrm{pp}}=1251.5 \mathrm{kN}$ and roof displacement at the performance point (pp), $\Delta_{\text {roof,pp }}=0.101 \mathrm{~m}$.

5.3.2. Calculation of Response Reduction Factor at the Performance Point. Table 19 shows different response reduction factors for MCE and DBE levels. These are calculated at different performance points (Figures 28-31).

From Table 19, response reduction factor of coupled shear walls is varying between 1.22 to 2.05 for maximum considered earthquake (MCE) level; which is almost same as the provision of CSA [25] for coupling beam with conventional reinforcement.

\section{Conclusions}

From the above studies, the following recommendations have been made for the design of coupled shear walls under earthquake motion.

(i) Design technique should be adopted for fixing the dimensions of coupled shear walls.

(ii) Coupled shear walls with $N \geq 15$ with equal storey height $h_{s}=3.6 \mathrm{~m}$ can be designed with an optimum ratio of $L_{b} / L_{w}=0.25$ for $L_{b} / d_{b}=1.25$ and $I_{b} / I=8 \times$ $10^{-03}$ to obtain consistency between the behavior with respect to the wall rotation and earthquake energy dissipations.

(iii) Pinned base condition can be provided at the base of the shear wall as this type of base condition offers better nonlinear behavior in compare to the fixed base condition.

(iv) The behavior of coupling beam should be governed by shear.

\section{Notations}

A: $\quad$ Area of symmetrical coupled shear walls

$A_{c w}$ : Area of concrete section of an Individual pier, horizontal wall segment, or coupling beam resisting shear in in ${ }^{2}$ as per ACI 318 [39]

$A_{g}$ : $\quad$ Gross area of concrete section in in ${ }^{2}$ For a hollow section, $A_{g}$ is the area of the concrete only and does not include the area of the $\operatorname{void}(\mathrm{s})$ as per ACI 318 [39]

$A_{s}^{\prime \prime}$ : $\quad$ Reinforcing steel in one diagonal as per Englekirk [3]

$A_{s}: \quad$ Area of nonprestressed tension reinforcement as per Englekirk [3]

$A_{s d}: \quad$ Reinforcement along each Diagonal of Coupling beam as per IS 13920 [13]

$A_{v d}$ : Total area of reinforcement in each group of diagonal bars in a diagonally reinforced coupling beam in in $^{2}$ as per ACI 318 [39]

$b_{b}: \quad$ Width of coupling beam

$b_{f}: \quad$ Flange width of I-beam as per FEMA 273 [14] and FEMA 356 [15]

$b_{w}$ : Web width of the coupling beam as per FEMA 273 [14] and FEMA 356 [15]

C: $\quad$ Compressive axial force at the base of wall 2

CP: $\quad$ Collapse prevention level

$D: \quad$ Overall depth of the steel I-coupling beam section

DC: $\quad$ Degree of coupling

DL: $\quad$ Dead loads

DBE: Design basis earthquake

$d: \quad$ Effective depth of the beam

$d_{b}: \quad$ Depth of the coupling beam

$d^{\prime}: \quad$ Distance from extreme compression fiber to centroid of compression reinforcement as per Englekirk [3]

$\Delta_{b}: \quad$ Displacement at $V_{b}$

$\Delta_{e}: \quad$ Elastic displacement $\left(\Rightarrow V_{e}\right)$

$\Delta_{l}: \quad$ Displacement at limiting response

$\Delta_{\text {roof: }}: \quad$ Roof displacement

$\Delta_{\text {roof,CP }}:$ Roof displacement at CP level

$\Delta_{\text {roof,yield: }}$ Roof displacement at yield level

$\Delta_{u}: \quad$ Displacement at ultimate strength capacity

$\Delta_{y}: \quad$ Displacement at yield strength capacity

$\Delta_{y_{a}}: \quad$ Actual displacement at $V_{y_{a}}$ 
$E_{c}$ : $\quad$ Modulus of elasticity of concrete

$E_{c b}: \quad$ Young's modulus for concrete in beam

$E_{\mathrm{cw}}$ : Young's modulus for concrete in wall

EPP: Elastic-perfectly-plastic

EQRD: Earthquake resistant design

$E_{s}$ : $\quad$ Modulus of elasticity of steel as per FEMA 273 [14] and FEMA 356 [15]

$E_{s b}: \quad$ Young's modulus for steel in beam

$E_{s w}$ : Young's modulus for steel in wall

$e: \quad$ Clear span of the coupling beam $+2 \times$ concrete cover of shear wall as per Englekirk [3]

$\varepsilon_{c}: \quad$ Strain in concrete

$F: \quad$ Force

$F_{1}$ : $\quad$ Maximum amplitude of triangular variation of loading

FEMA: Federal emergency management agency

$F_{u}: \quad$ Ultimate force

$F_{y}: \quad$ Yield stress of structural steel

$f_{c}^{\prime}$ : $\quad$ Specified compressive strength of concrete cylinder

$f_{c k}: \quad$ Characteristic compressive strength of concrete cube

$f_{y}$ : $\quad$ Specified yield strength of reinforcement

$H$ : $\quad$ Overall height of the coupled shear walls

$h$ : $\quad$ Distance from inside of compression flange to inside of tension flange of I-beam as per FEMA 273 [14] and FEMA 356 [15]

$h_{s}: \quad$ Storey height

I: $\quad$ Moment of inertia of symmetrical coupled shear walls

$I_{b}$ : $\quad$ Moment of inertia of coupling beam

IO: Immediate occupancy level

$i$ : $\quad$ Storey number

$k$ : Unloading stiffness

$k_{1}$ : $\quad$ Postyield stiffness

$k_{e}: \quad$ Elastic stiffness

$k_{i}$ : $\quad$ Initial stiffness

$k_{\text {sec }}$ : Secant stiffness

$L_{b}$ : Length of the coupling beam

$L_{d}$ : Diagonal length of the member

LL: $\quad$ live loads

LS: $\quad$ Life safety level

$L_{w}$ : Depth of coupled shear walls

$l$ : $\quad$ Distance between neutral axis of the two walls

$\lambda_{0}$ : Member over strength factor as per Englekirk [3]

M: $\quad$ Moment of symmetrical coupled shear walls

$M_{1}$ : $\quad$ Moment at the base of the wall 1

$M_{2}$ : Moment at the base of the wall 2

MCE: Maximum considered earthquake

MDOF: Multi-degree of freedom

$M_{n}$ : Nominal flexural strength at section in lb-in as per ACI 318 [39]

$M_{p}: \quad$ Moment capacity of coupling beam as per Englekirk [3]

$M_{\mathrm{ot}}$ : Total overturning moment due to the lateral loading

MRF: Moment resistant frame $\mu$ : Displacement ductility capacity relied on in the

$\mu_{\Delta}: \quad$ Ductility

$\mu_{\Delta e 1}$ : Energy based proposal for ductility under monotonic loading and unloading

$\mu_{\Delta e 2}$ : $\quad$ Energy based proposal for ductility under cyclic loading

N: $\quad$ Total number of storeys

NA: $\quad$ Not applicable

NEHRP: National earthquake hazard reduction program

NSP: Non-linear static procedure

$P: \quad \quad$ Axial force as per IS 456 [19]

PBSD: Performance based seismic design

$p$ : $\quad$ Percentage of minimum reinforcement

$\phi$ : $\quad$ Shear span to depth ratio

pp: $\quad$ Performance point

$R: \quad$ Response reduction factor

RCC: $\quad$ Reinforced cement concrete

$R_{d}$ : Ductility related force modification factor

$R_{\mu}$ : $\quad$ Ductility factor

$R_{R}: \quad$ Redundancy factor

$R_{s}: \quad$ Overstrength factor

$S_{a}: \quad$ Spectral acceleration

$S_{d}: \quad$ Spectral displacement

SDOF: Single-degree of freedom

$T$ : $\quad$ Tensile axial force at the base of wall 1

$T_{1}$ : $\quad$ Tensile strength of One diagonal of a diagonal reinforced coupling beam

$T_{d}$ : Tensile strength of truss reinforced coupling beam's diagonal as per Englekirk [3]

$T^{\prime}$ : $\quad$ The residual chord strength as per Englekirk [3]

$t_{f}$ : $\quad$ Flange thickness of steel I-coupling beam as per Englekirk [3]

$\theta: \quad$ Inclination of diagonal reinforcement in coupling beam

$\theta_{b}: \quad$ Coupling beam rotation

$\theta_{l u}: \quad$ Rotational value at ultimate point

$\theta_{u, \max }: \quad$ Maximum rotational value

$\theta_{w}: \quad$ Wall rotation

$\theta_{y}$ : $\quad$ Yield rotation as per FEMA 273 [14] and FEMA 356 [15]

$t_{w}: \quad$ Wall thickness

$t_{w^{\prime}}: \quad$ Web thickness of steel I-coupling beam

$V: \quad$ Shear force in the coupling beam

$V_{1}$ : The shear or vertical component of one diagonal in a primary truss travelled along the compression diagonal as per Englekirk [3]

$V_{2}$ : The shear in a secondary truss produced by the residual tension reinforcement activated the load transfer mechanism as per Englekirk [3]

$V_{B}: \quad$ Base shear

$V_{b}: \quad$ Non-factored design base shear

$V_{d}: \quad$ Factored design base shear may be less than or greater than $V_{y_{a}}$

$V_{e}: \quad$ Base shear for elastic response

$V_{l}$ : $\quad$ Base shear at limiting response

$V_{n}: \quad$ Nominal shear strength in $\mathrm{lb}$ as per ACI 318 [39] 
$V_{n f}$ : The transferable shear force for flexure dominant steel coupling beam as per Englekirk [3]

$V_{s p}$ : Shear capacity of coupling beam as per Englekirk [3]

$V_{s 1}$ : Shear strength of closed stirrups as per ATC 40 [16], FEMA 273 [14] and FEMA 356 [15]

$V_{u}$ : Capacity corresponding to $\Delta_{u}$ (may be the maximum capacity)

$V_{u 1}$ : Factored shear force as per IS 13920 [13]

$V_{u 2}$ : Factored shear force at section in $\mathrm{lb}$ as per ACI 318 [39]

$V_{w}$ : Shear force at the base of the shear wall

$V_{w 1}$ : Shear force at the base of wall 1

$V_{w 2}$ : Shear force at the base of wall 2

$V_{y}$ : Base shear at idealized yield level

$V_{y_{a}}$ : Actual first yield level

$v_{n}$ : Total nominal shear stress in $\mathrm{MPa}$ as per NZS $3101[40]$

$W_{g}$ : Total gravity loading for symmetrical coupled shear walls

$w$ : Compressive strut width as per Englekirk [3]

$Z$ : Zone factor

$Z_{p}$ : Plastic section modulus of steel coupling beam.

\section{References}

[1] Bureau of Indian Standards, "Criteria for earthquake resistant design of structures, part 1: general provisions and buildings," Tech. Rep. IS-1893, part 1, Bureau of Indian Standards, New Delhi, India, 2002.

[2] A. K. Jain, Reinforced Concrete Limit State Design, Nem Chand \& Bros, Roorkee, India, 1999.

[3] R. E. Englekirk, Seismic Design of Reinforced and Precast Concrete Buildings, John Wiley, New York, NY, USA, 2003.

[4] R. Park and T. Paulay, Reinforced Concrete Structures, John Wiley \& Sons, New York, NY, USA, 1975.

[5] G. G. Penelis and A. J. Kappos, Earthquake-Resistant Concrete Structures, E\&FN SPON, New York, NY, USA, 1997.

[6] B. S. Smith and A. Coull, Tall Building Structures (Analysis and Design), John Wiley and Sons, New York, NY, USA, 1991.

[7] P. J. Fortney and B. M. Shahrooz, "Boundary detailing of coupled core wall system wall piers," Advances in Structural Engineering, vol. 12, no. 3, pp. 299-310, 2009.

[8] K. A. Harries and D. S. McNeice, "Performance-based design of high-rise coupled wall systems," Structural Design of Tall and Special Buildings, vol. 15, no. 3, pp. 289-306, 2006.

[9] S. El-Tawil, K. A. Harries, P. J. Fortney, B. M. Shahrooz, and Y. Kurama, "Seismic design of hybrid coupled wall systems: state of the art," Journal of Structural Engineering, vol. 122, no. 12, pp. 1453-1458, 2010.

[10] T. Paulay and M. J. N. Priestley, Seismic Design of Reinforced Concrete and Masonry Buildings, John Wiley \& Sons, New York, NY, USA, 1992.

[11] F. Naiem, The Seismic Design Handbook, Kluwer Academic, Boston, Mass, USA, 2001.

[12] Bureau of Indian Standards, "Earthquake resistant design and construction of buildings-code of practice," Tech. Rep. IS4326, Bureau of Indian Standards, New Delhi, India, 1993.
[13] Bureau of Indian Standards, "Ductile detailing of reinforced concrete structures subjected to seismic forces-code of practice," Tech. Rep. IS-13920, Bureau of Indian Standards, New Delhi, India, 1993.

[14] Federal Emergency Management Agency, "NEHRP guidelines for the seismic rehabilitation of buildings," Tech. Rep. FEMA273, Federal Emergency Management Agency, Washington, DC, USA, 1997.

[15] Federal Emergency Management Agency, "Prestandard and commentary for the seismic rehabilitation of buildings," Tech. Rep. FEMA-356, Federal Emergency Management Agency, Washington, DC, USA, 2000.

[16] Applied Technology Council, "Seismic evaluation and retrofit of concrete buildings," Tech. Rep. ATC-40, Applied Technology Council, Redwood City, Calif, USA, 1996, Volume I.

[17] L. Galano and A. Vignoli, "Seismic behavior of short coupling beams with different reinforcement layouts," ACI Structural Journal, vol. 97, no. 6, pp. 876-885, 2000.

[18] ATENA2D: Version 3.3.0.3, Nonlinear Finite Element Integrated Analysis, Cervenka Consulting, Praha, Czech Republic, 2006.

[19] Bureau of Indian Standards, "Plain and reinforced concretecode of practice," Tech. Rep. IS-456, Bureau of Indian Standards, New Delhi, India, 2000.

[20] Bureau of Indian Standards: IS-456, "Design aids for reinforced concrete," Tech. Rep. SP-16, Bureau of Indian Standards, New Delhi, India, 1978.

[21] V. Prakash, "Whither performance-based engineering in India?” ISET Journal, vol. 41, no. 1, pp. 201-222, 2004.

[22] V. Prakash, G. H. Powell, and S. Campbell, DRAIN-3DX Base Program User Guide Version 1.10, Structural Engineering, Mechanics and Materials, Department of Civil Engineering UC, Berkeley, Calif, USA, 1993.

[23] SAP2000: Advanced 10.0.5, Static and Dynamic Finite Element Analysis of Structures, Computers and Structures Inc., Berkeley, Calif, USA, 2006.

[24] S. M. Pore, Performance Based Seismic Design of Low to Medium Rise RC Framed Buildings for India, Department of Earthquake Engineering, IIT Roorkee, Roorkee, India, 2007.

[25] Canadian Standards Association, "Design of concrete structures for buildings," CSA CAN3-A23. 3-M94, Canadian Standards Association, Rexdale, Canada, 1994.

[26] American Institute of Steel Construction, Inc., Seismic Provisions for Structural Steel Buildings, American Institute of Steel Construction, Inc, Chicago, Ill, USA, 1997.

[27] American Institute of Steel Construction, Inc., Seismic Provisions for Structural Steel Buildings, Supplement No. 2, American Institute of Steel Construction, Inc., Chicago, Ill, USA, 2000.

[28] American Institute of Steel Construction, Inc., Seismic Provisions for Structural Steel Buildings, American Institute of Steel Construction, Inc, Chicago, Ill, USA, 2005.

[29] T. Paulay, "The design of ductile reinforced concrete structural walls for earthquake resistance," Earthquake Spectra, vol. 2, no. 4, pp. 783-823, 1986.

[30] K. A. Harries, D. Mitchell, W. D. Cook, and R. G. Redwood, "Seismic response of steel beams coupling concrete walls," Journal of Structural Engineering, vol. 119, no. 12, pp. 3611-3629, 1993.

[31] T. Paulay, "A displacement-focused seismic design of mixed building systems," Earthquake Spectra, vol. 18, no. 4, pp. 689718, 2002. 
[32] T. Paulay, "The displacement capacity of reinforced concrete coupled walls," Engineering Structures, vol. 24, no. 9, pp. 11651175, 2002.

[33] R. A. Hindi and R. G. Sexsmith, "A proposed damage model for RC bridge columns under cyclic loading," Earthquake Spectra, vol. 17, no. 2, pp. 261-281, 2001.

[34] G. Xuan, B. M. Shahrooz, K. A. Harries, and G. A. Rassati, "A performance-based design approach for coupled core wall systems with diagonally reinforced concrete coupling beams," Advances in Structural Engineering, vol. 11, no. 3, pp. 265-280, 2008.

[35] S. Chao, K. Khandelwal, and S. El-Tawil, "Ductile web fracture initiation in steel shear links," Journal of Structural Engineering, vol. 132, no. 8, pp. 1192-1200, 2006.

[36] J. A. Munshi and S. K. Ghosh, "Displacement-based seismic design for coupled wall systems," Earthquake Spectra, vol. 16, no. 3, pp. 621-642, 2000.

[37] O. Chaallal, D. Gauthier, and P. Malenfant, "Classification methodology for coupled shear walls," Journal of Structural Engineering, vol. 122, no. 12, pp. 1453-1458, 1996.

[38] I. A. Macleod, Lateral Stiffness of Shear Walls with Openings, Department of Civil Engineering, Glasgow University, Glasgow, UK, 1966.

[39] American Concrete Institute, "Building code requirements for reinforced concrete and commentary," Tech. Rep. ACI 31805/ACI 318R-05, American Concrete Institute, Farmington Hills, Mich, USA, 2005.

[40] New Zealand Standard, "The design of concrete structures," Tech. Rep. NZS, 3101 (part 1), New Zealand Standard, Wellington, New Zealand, 1995. 

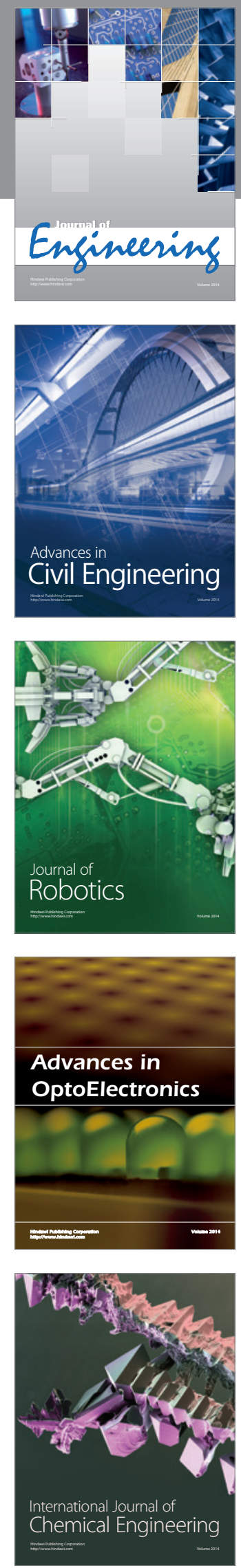

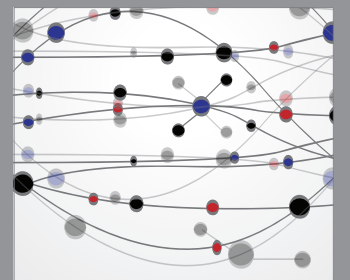

The Scientific World Journal
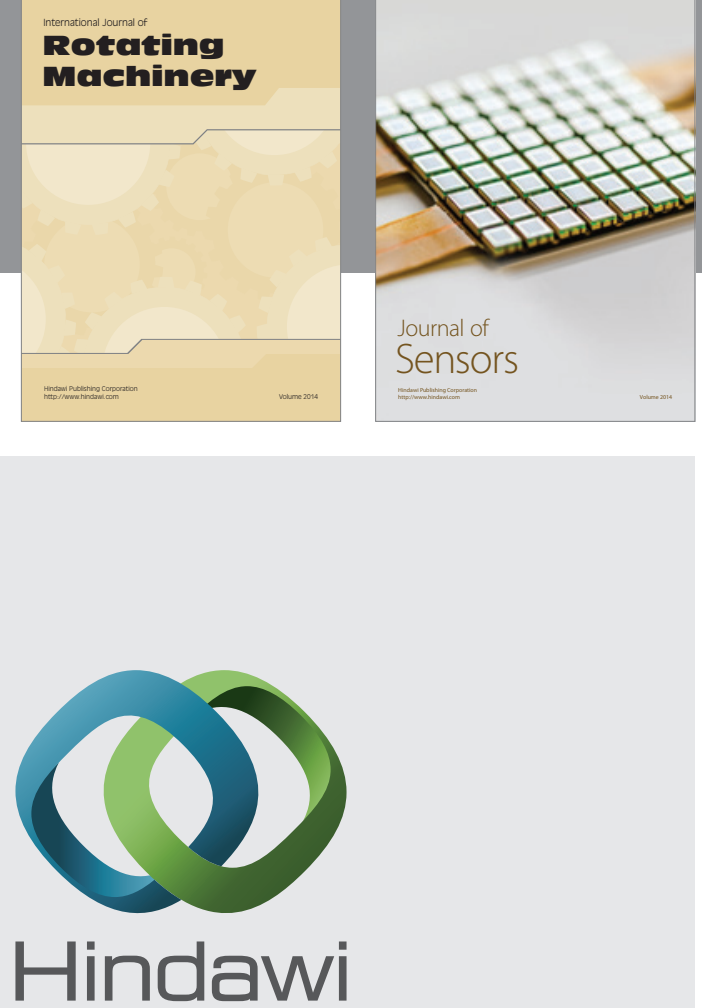

Submit your manuscripts at http://www.hindawi.com
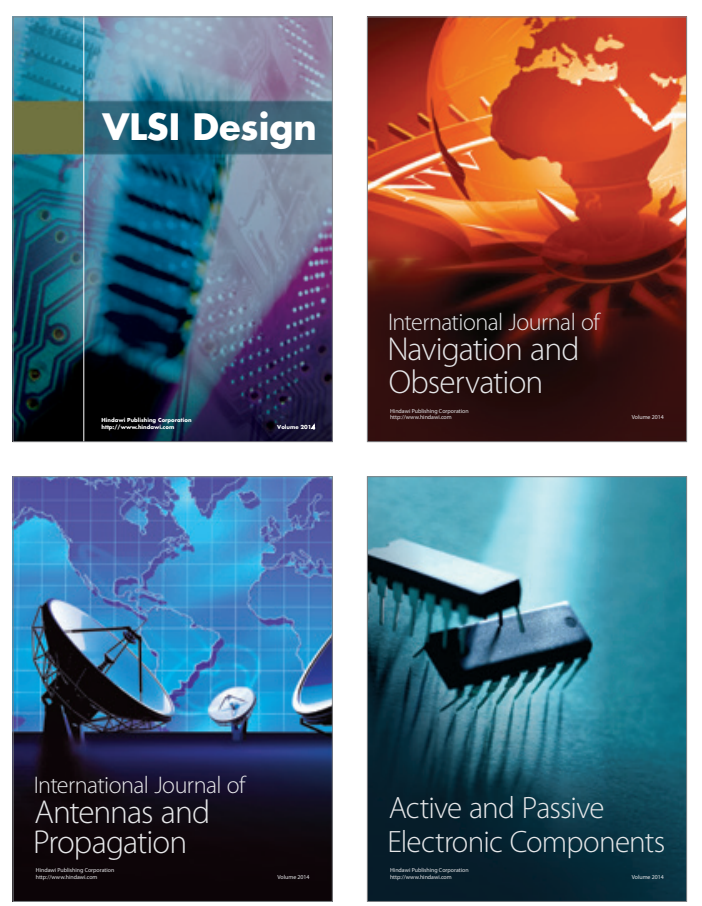
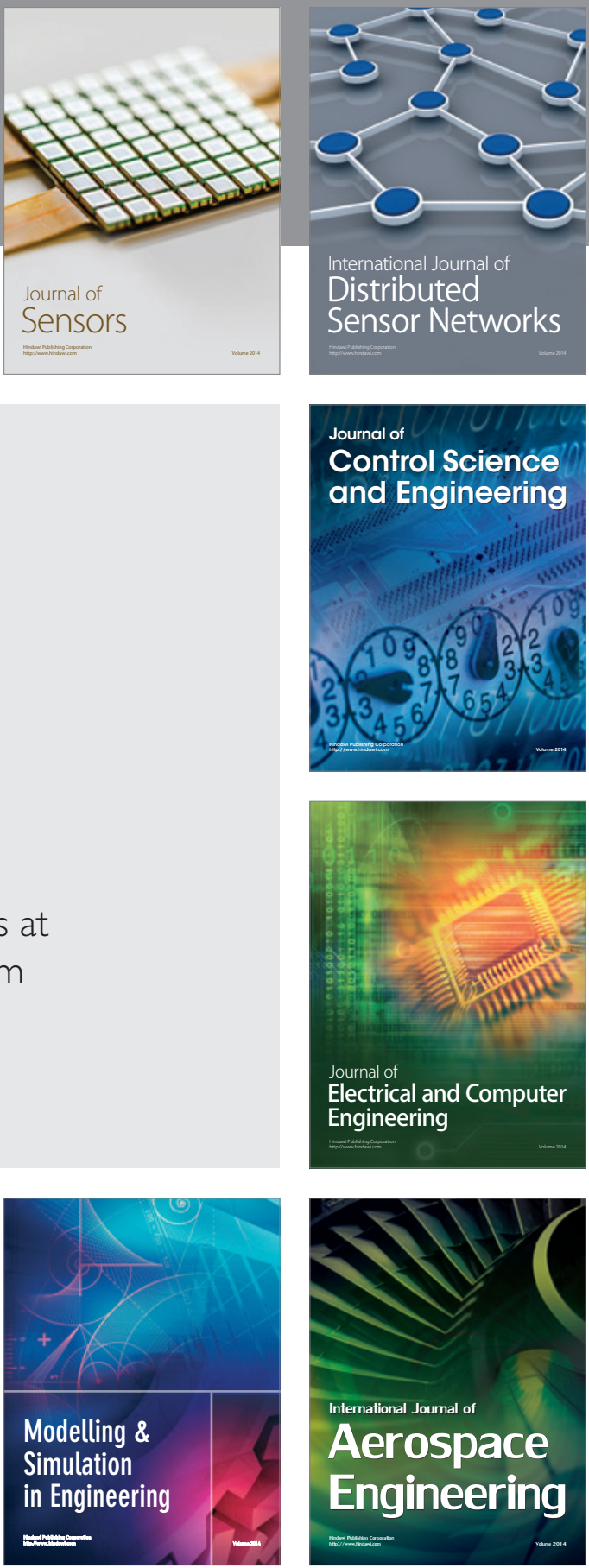

Journal of

Control Science

and Engineering
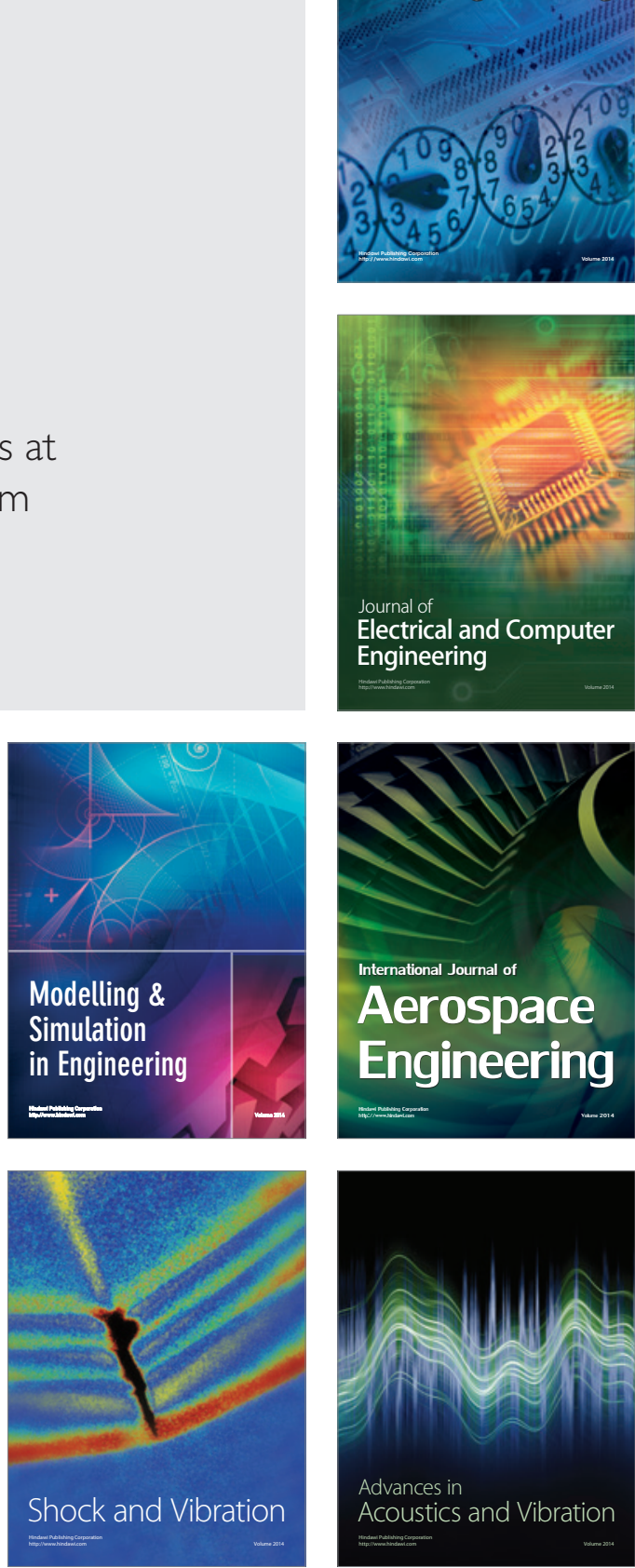